\title{
Fed-Batch Decolourization of Mixture of Brilliant Green and Evans Blue by Bacteria Species Applied as Pure and Mixed Cultures: Influence of Growth Conditions
}

\author{
Ewa Zabłocka-Godlewska (D) Wioletta Przystaś
}

Received: 11 November 2019 / Accepted: 24 January 2020 /Published online: 3 February 2020

(C) The Author(s) 2020

\begin{abstract}
Synthetic dyes, generally resistant, toxic and carcinogenic presents a substantial risk to the environment and health of human. The present study was aimed to decolourize a dye mixture (Evans blue and brilliant green) by selected bacterial strains cultivated at different growth conditions (e.g. unmodified, correction of $\mathrm{pH}$ value and supplementation with nutrients). The bacterial strains used as pure and mixed cultures include facultative anaerobes Aeromonas hydrophila (Abs37), Citrobacter sp. (Cbs50) and obligatory aerobe Pseudomonas putida (Pzr3). The efficiency of removal of all successive doses of dye mixture (4-5 doses, total load 170-200 mg/l) was tested in static conditions in fedbatch bioreactors. The modification of bacteria growth conditions influenced on decolourization efficiency: most advantageous was $\mathrm{pH}$ value correction combined with nutrient supplementation then $\mathrm{pH}$ correction alone
\end{abstract}

E. Zabłocka-Godlewska · W. Przystaś

Faculty of Energy and Environmental Engineering, The Silesian University of Technology, Akademicka 2A, 44-100 Gliwice,

Poland

W. Przystaś

e-mail: wioletta.przystas@polsl.pl

E. Zabłocka-Godlewska

Environmental Biotechnology Department, Silesian University of Technology, Akademicka 2A, 44-100 Gliwice, Poland

E. Zabłocka-Godlewska $(\bowtie) \cdot$ W. Przystaś

Biotechnology Center, The Silesian University of Technology, B. Krzywoustego 8, 44-100 Gliwice, Poland e-mail: ewa.zablocka-godlewska@polsl.pl and nutrient supplementation (final removal results 95.6-100\%, 92.9-100\% and 89.1-97.2\%, respectively). The mixed bacterial cultures removed the total load of dyes with higher efficiency than pure strains (final removal $95.2-100 \%$ and $84.0-98.2 \%$, respectively). The best results were obtained for the mixture of facultative anaerobe Citrobacter sp. and obligatory aerobe Pseudomonas putida which removed the highest load of dye mixture $(200 \mathrm{mg} / \mathrm{l}$ introduced at five doses) in the shortest time $(288 \mathrm{~h})$, while the others pure and mixed cultures needed 425-529 h for removal four doses of dye mixture (total load $170 \mathrm{mg} / \mathrm{l}$ ). The zoo- and phytotoxicity decreased after these processes (from $\mathrm{V}$ class of toxicity (extremely toxic) even to II class (low toxicity)). The main mechanisms of decolourization was biotransformation/biodegradation, supported by sorption.

Keywords Decolourization · Fed-batch reactor . Synthetic dye mixture - Azo and triphenylmethane dyes . Mixed bacterial culture $\cdot$ Ecotoxicity

\section{Introduction}

The common usage of synthetic dyes is a result of contemporary consumer needs, including low-costs, the uncomplicated manufacture of a wide spectrum of colours, and the durability of colouration. Sectors of the economy which use synthetic dyes include textile, food, pharmacy, and even the electronics industry and others (Hamid and Rehman 2009; Koyani et al. 2013; Somasiri et al. 2006; Tony et al. 2009; Younes et al. 2012). The 
most popular class of applied dyes is azo dyes, which accounts for about $70 \%$ of all used colourants. Another relatively common chemical group of dyes are triphenylmethanes. The dyeing process is always associated with the loss of part of the applied dyes; annually about $40 \%$ of their mass may be released into wastewater. From the textile industry alone, the annual discharge of dyes into wastewater may reach 280,000 tons (Ali 2010; Ghaly et al. 2014; Oliveira et al. 2007).

The increasing amount of dyes used annually can lead to serious global environmental problems. The main source of surface water contamination from dyes are discharges of inefficiently cleaned wastewaters generated during the production of dyes as well as during their application in industry. The efficiency of the treatment of dyed wastewaters by conventional processes depends on the substance properties, such as complexity of their aromatic chemical structure, and their relative resistance to physical, chemical, and biological factors. All these lead to their accumulation in the environment. The increasing concentration of synthetic dyes in the environment causes direct, as well as indirect adverse impacts, especially on surface water ecosystems and human health. The contamination of surface waters with dyes causes, among other things, limited light penetration and photosynthetic activity, and may lead to oxygen deficiency in water ecosystems. Many of these chemicals are toxic, mutagenic, resistant to biological degradation, and may be bioaccumulated (Cao et al. 2019; Eskandari et al. 2019; Hamid and Rehman 2009; Koyani et al. 2013).

Various physicochemical methods to treat coloured sewage are currently available (e.g. oxidation, reverse osmosis, adsorption, flotation, precipitation, and coagulation). Even though they are very effective, their application is limited by high costs and energy consumption, and the production of toxic by-products and sludge (Hamid and Rehman 2009; Koyani et al. 2013; Meerbergen et al. 2018; Tony et al. 2009). Such limitations are not associated with biological methods based on microbial processes. These methods are more attractive and are significantly less environmentally harmful (Eskandari et al. 2019; Koyani et al. 2013; Meerbergen et al. 2018; Saratale et al. 2011; Singh et al. 2010; Srinivasan and Viraraghavan 2010; Tony et al. 2009; Wang et al. 2012; Younes et al. 2012; ZabłockaGodlewska et al. 2012). The efficiency of these processes depends on the type of microorganisms used, as well as the process conditions. The most important factors are temperature, oxygenation, $\mathrm{pH}$ value, available carbon and nitrogen sources, and the concentration of the dye and its chemical structure (Eskandari et al. 2019; Hamid and Rehman 2009; Koyani et al. 2013; Meerbergen et al. 2018; Przystaś et al. 2015; Saratale et al. 2011; Tony et al. 2009; Younes et al. 2012; Zabłocka-Godlewska et al. 2009). The properties of the microorganisms used at biological cleaning technologies, having a substantial influence on the process' efficiency, are the wide spectrum of metabolic abilities, adaptability, easy activity maintenance at fluctuated growth conditions and short generation time. The biochemical mechanisms underlying the decolourization of azo dyes by bacteria have been well elucidated, whereas, in the case of triphenylmethane dyes, they are not well documented. However, it is known that during the biodegradation processes of dyes from both of these groups, co-metabolic reactions are likely to be the main mechanisms of dye reduction (Eskandari et al. 2019; Jang et al. 2005; Pandey et al. 2007; Wu et al. 2012; Wang et al. 2012). Microbial decolourization of synthetic dyes strongly depends on the presence and availability of a suitable co-substrate. Bacterial degradation of dyes without supplementation by additional carbon and nitrogen sources is very difficult (Karim et al. 2018; Meerbergen et al. 2018; Solis et al. 2012). It was reported that the composition of the growth medium is critical to the efficiency of microbial decolourization. However, in some cases, additional carbon sources may repress the decolourization process. In the presence of more easily available carbon sources, the genes responsible for enzyme biosynthesis, required for utilization of the secondary carbon sources, may not be expressed (Karim et al. 2018; Meerbergen et al. 2018; Solis et al. 2012).

Wang et al. (2009) reported the important role of additional carbon sources. In the presence of glucose, 90\% of Reactive Red 180 was removed by Citrobacter sp. CK3, whereas in the absence of glucose only $26.7 \%$ decolourization was observed. Modi et al. (2010) showed that different carbon sources may have a different effect on decolourization. For example, in the presence of sucrose, $82 \%$ decolourization of Reactive Red 195 was reached, whereas, for xylose, only $25 \%$ was achieved. Yeast extract has been found to be one of the best nitrogen sources for decolourization processes (Chen et al. 2003; Eskandari et al. 2019; Meerbergen et al. 2018; Moosvi et al. 2005).

Among the few factors that impact bacterial decolourization efficiency, $\mathrm{pH}$ value is particularly 
important. This factor determines the growth of bacteria biomass, their enzymatic activity, bioavailability of dyes as a carbon source, and the possibility of sorption of dyes by biomass (Eskandari et al. 2019; Kodam et al. 2005; Meerbergen et al. 2018; Solis et al. 2012). It was observed that when the initial $\mathrm{pH}$ was about 4.5 , the cell mats of Aeromonas hydrophila were deeply coloured due to the adsorption of dyes. The adsorption of dyes on the cell surface may be related to the neutralization of its charge. In general, dyes in solution are negatively charged in opposition to cells, which tend to possess a positive charge at lower $\mathrm{pH}$. This may cause the cells to have a relatively higher affinity for the dyes (Chen et al. 2003). Meerbergen et al. (2018) studied ability to remove Reactive Orange 16 and Reactive green 19 by six bacteria strains (Klebsiella sp., two strains from genera Pseudomonas, three strains from genera Acinetobacter), all of these strains obtained the highest decolourization results at $\mathrm{pH}$ 7.0. A further increase or decrease of $\mathrm{pH}$ in range 4-10 significantly decreased the efficiency of decolourization of both studied dyes.

Conventional wastewater treatment technologies use activated sludge, which is a complex population of microorganisms, mainly bacteria. Unfortunately, these technologies are relatively inefficient. (Hamid and Rehman 2009; Koyani et al. 2013; Meerbergen 2018; Przystaś et al. 2012; Saratale et al. 2011; Tony et al. 2009; Wang et al. 2012; Younes et al. 2012; ZabłockaGodlewska et al. 2009).

The increase of the efficiency of biological decolourization may be achieved by bioaugmentation of the treatment system by a multiplied biomass of selected bacterial strains and optimization of their growth conditions. The main condition of the successful bioaugmentation is enrichment of these systems with microorganisms carefully selected in term of their high decolourization potential and adaptability. The selection of the bacteria strains and their mixtures to use them in the future as the potential components of the bio preparations was the main goal of the presented study.

Wastewaters may contain a mixture of dyes from different chemical groups. Relatively few studies on the removal of dye mixtures by mixed cultures have been conducted. Most previous research has focused on the decolourization of single dyes by pure bacterial cultures (Ito et al. 2018; Meerbergen et al. 2018; Saratale et al. 2009; Singh et al. 2010; Tony et al. 2009; Vijaykumar et al. 2007). In this research, the possibilities of removal of particular dye mixture (azo Evans blue and triphenylmethane brilliant green) by previously selected pure and mixed bacterial cultures were assessed. This dye mixture has not been examined up to now, with the exception of other studies by the authors (e.g. Przystaś et al. 2013; Zabłocka-Godlewska et al. 2014; Zabłocka-Godlewska et al. 2015). The choice for study the Evans blue and brilliant green was firstly dictated by the fact that they are representatives of two most popular classes of applied dyes, secondly due to the common use exactly these dyes we can expect their presence in the wastewaters and then in aquatic ecosystems. The triphenylmethane brilliant green (classified as hazardous substance), is used at the textile industry for dying the silk, wool, cotton, leather and polymers, in laboratories for preparation staining, because of the antiseptic properties, at the past was used in medicine (Oranusi and Ogugbue 2005; Rehman et al. 2015). The disazo Evans blue (classified as nontoxic substance), is commonly used in medicine for estimation the blood and plasma volume, the permeability of the blood-brain barrier to macromolecules, more over at diagnostics of damages of backbone and muscles and for preparation staining and others. In unchanged form is excreted with the urine to wastewaters (Jagusiak and Pańczyk 2019; Kaptanoglu et al. 2004; Hmer et al. 2002).

The investigation with usage of both pure and mixed bacterial cultures was conducted in fed-batch bioreactors in various growth conditions which included the $\mathrm{pH}$ value correction and supplementation with nutrients. It should be emphasized that the environmental safety of decolourization processes is also very important. Data in this area are limited, so an additional goal of this study was an evaluation of the ecotoxicological impact of the post-process solutions on aquatic organisms.

\section{Materials and Methods}

\subsection{Dyes Used in the Studies}

The investigation was conducted using two synthetic dyes from different chemical groups:

- $\quad$ azo dyes - Evans blue (EB) (Sigma-Aldrich);

- and triphenylmethane dyes - brilliant green (BG) (Sigma-Aldrich). 
Across all experiments, these dyes were used together as a mixture. Dye mixture solutions were prepared in sterile distilled water in the ratio $\mathrm{BG}: \mathrm{EB}=1: 1(\mathrm{w} / \mathrm{w})$. The mixture was sterilized mechanically by cellulose syringe filters (pore diameter $0.2 \mu \mathrm{m}$ ). Dye solutions were stored in refrigerator $\left(\right.$ at $\left.4{ }^{\circ} \mathrm{C}\right)$ in dark glass bottles prior to use. Various concentrations of the mixture were prepared. For the dye concentration test, this ranged from 20 to $120 \mathrm{mg} / \mathrm{l}$. For the main decolourization experiment, the initial concentration was $80 \mathrm{mg} / \mathrm{l}$ and subsequent doses were at concentrations of $30 \mathrm{mg} / \mathrm{l}$.

The absorbance spectrum of the dye mixture was examined using a spectrophotometer UV-VIS Hitachi 1900 (wavelength ranged from 190 to $1100 \mathrm{~nm}$ ). The maximum absorbance wavelength for the studied mixture was determined $(\lambda=591 \mathrm{~nm})$ using the peak with the strongest absorption. The structure of each dye, their summary formulas, and experimentally-determined wavelengths corresponding to the maximum absorbance of a single dye, as well as the mixture, are presented in Table 1.

\subsection{The Growth Media and Diluent}

Pure and mixed bacterial strains were cultivated on liquid and solid Kimura medium (Zabłocka-
Godlewska et al. 2012). The $\mathrm{pH}$ of the medium was adjusted to 6.8-7.0. Bacteriological agar (18 g/l) (BTL) was used for the preparation of the solid media. Samples (e.g. sewage, river water) and biomass suspensions were diluted in a sterile physiological saline $(0.85 \%$ water solution of $\mathrm{NaCl}$ ). Slants prepared from the nutrient agar (BTL) were used for the storage of bacterial strains and the multiplication of their biomass.

\subsection{Isolation and Identification of Bacterial Strains and Preparation of Inoculum}

The bacterial strains used in the decolourization studies were isolated from different sites located in south Poland. Aeromonas hydrofila (Abs37) and Citrobacter sp. (Cbs50) were isolated from the aeration chamber of two different municipal wastewater treatment plants (Gliwice and Katowice, respectively). Pseudomonas putida was isolated from the polluted river water of Kłodnica in Gliwice. Isolation was done on Petri dishes with the solid Kimura medium supplemented with dyes (disazo Evans blue or triphenylmethane brilliant green) in $50 \mathrm{mg} / \mathrm{l}$ concentrations. The diluted samples (at range $10^{-1}-10^{-6}$ ) were spread on plates with this medium according to the standard spread plate method (Sanders 2012). Samples were incubated for $96 \mathrm{~h}$ at a

Table 1 Characteristic of used synthetic dyes

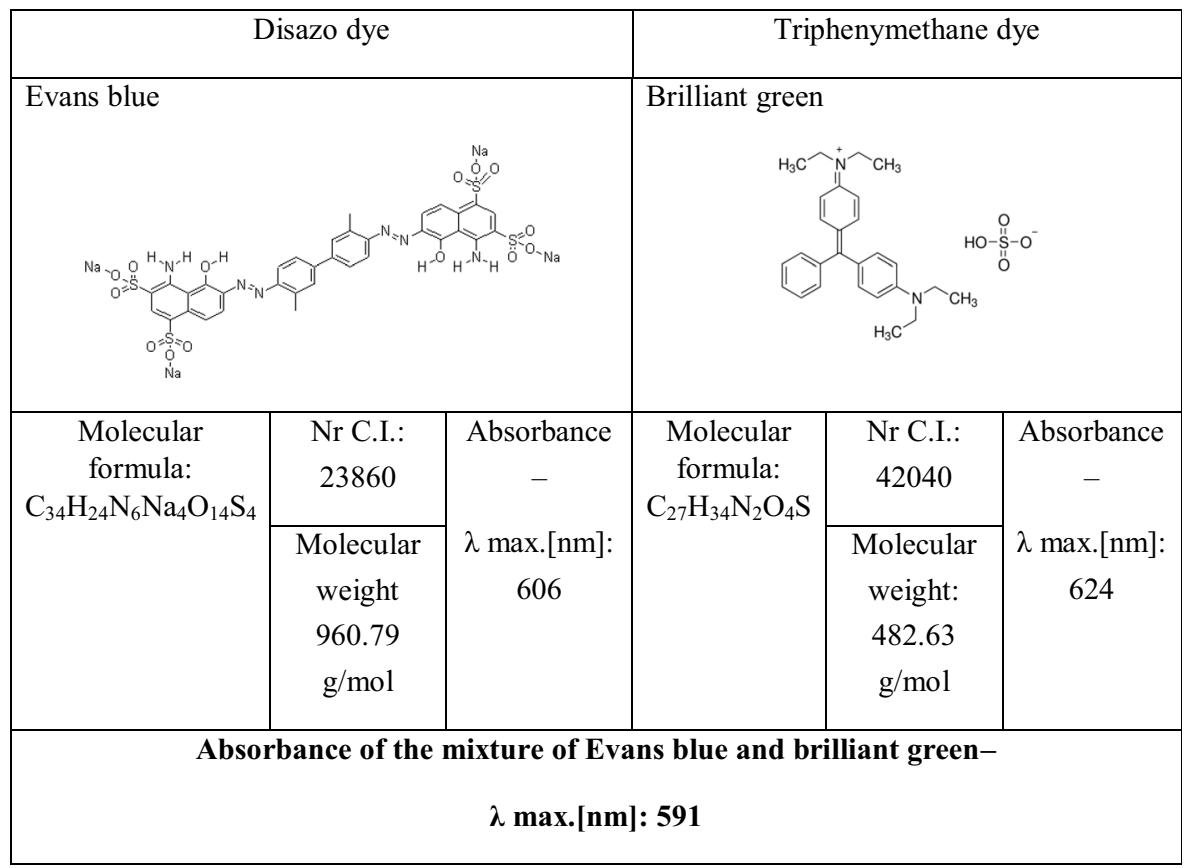


temperature of $26^{\circ} \mathrm{C}$. Based on the features of growth on plates for further studies, three bacterial strains were chosen. All of them grew with a visible decolourized zone around the colony and two of them (Abs37 and Cbs50) additionally had strongly dyed biomass. These strains were passed onto the sterile nutrient agar and underwent the purification procedure (Sanders 2012). After purification, all selected strains were identified by API 20E and API 20NE tests (Biomerieux). The pure cultures of isolated bacteria were cultivated on nutrient agar slants with the aim of multiplying their biomass for further stages of screening (Sanders 2012).

The inoculum of bacterial strains was prepared from 48 h slants (Nutrient Agar (Fluka Biochemika)) and rinsed with the sterile physiological salt solution. The optical density (OD) of each suspension was measured with the use of both the McFarland Standards and the spectrophotometric method (absorbance at $\lambda=600 \mathrm{~nm}$ ) and was adjusted to a value of $\sim 15 \times 10^{8} \mathrm{cfu} / \mathrm{ml}(5 \mathrm{MFU})$ what corresponded with the $\mathrm{OD}_{600}$ ranging from $0.58-0.62$.

\subsection{Antagonistic Tests}

Antagonistic tests were conducted before the bacterial cultures were mixed. Tests were performed on Petri dishes with solid nutrient agar by cross streak method which is used for rapid screen of antagonisms between microorganisms (Balouiri et al. 2016). The antagonistic plate tests demonstrated a lack of negative interactions between the studied microorganisms, allowing for their use in the preparation of mixed cultures.

\subsection{Concentration Test}

The influence of dye mixture concentration on decolourization efficiency was estimated across five levels of concentration (i.e. 20, 40, 60, 80, 100 and $120 \mathrm{mg} / \mathrm{l}$ ). The dye mixture was prepared at an equal proportion (1:1) of Evans blue and brilliant green. The concentration test was done in triplicate, in tubes with liquid Kimura medium. The tubes were inoculated with $0.1 \mathrm{ml}$ of proper bacterial suspension $(\sim$ $\left.15 \times 10^{8} \mathrm{cfu} / \mathrm{ml}\right)$. The proper volume of the filtersterilized dye mixture was added to tubes containing $10 \mathrm{ml}$ of 48-h-old cultures in a stationary growth phase. The control samples were prepared in the same way, but without biomass. After incubation for 6 days at $26{ }^{\circ} \mathrm{C}$, samples were centrifuged
(5000 rpm/10 $\mathrm{min}$ ), and absorbance of obtained supernatants was measured spectrophotometrically on UV-Vis Hitachi U-1900 (determined optimum wavelength for dye mixture was $\lambda=591 \mathrm{~nm}$ ). Percentage of dye removal was calculated according to formula:

$R=(C-S / C) \times 100 \%$

$R \quad$ dye mixture removal [\%]

$C$ concentration of dye in a control sample without biomass [mg/l]

$S$ residue concentration of dye in sample with bacteria biomass $[\mathrm{mg} / \mathrm{l}]$

\subsection{Study of Decolourization of Dye Mixture}

The decolourization study was conducted in static conditions in fed-batch bioreactors with a volume of $2 \mathrm{~L}$ and a content of $1.5 \mathrm{~L}$ of Kimura growth medium. The studies were conducted in the followed series: without changes (i.e. no modifications or ' $\mathrm{nm}$ '), with $\mathrm{pH}$ correction (' $\mathrm{pH}$ '), with dosage of additional portions of the Kimura growth medium ('sm'), with pH correction combined with supplementation with the Kimura growth medium (' $\mathrm{pH}+$ sm'), and with no modifications and dead biomass for sorption estimation ('db')) (Table 2).

During the first stage of studies, pure bacterial cultures were used. The strains used in the studies were: the facultative anaerobes Aeromonas hydrophila (Abs37) and Citrobacter sp. (Cbs50), and the obligatory aerobe Pseudomonas putida (Pzr3). At the second stage, mixed cultures were used. There were three mixture of strains prepared as follows: Abs37+Cbs50, Abs37+Pzr3, Cbs50+Pzr3.

The bacterial suspensions prepared previously were used for reactor inoculation. At the first stage of each experiment, $15 \mathrm{ml}$ of proper single-strain suspension (bacteria concentration $\sim 15 \times 10^{8} \mathrm{cfu} /$ $\mathrm{ml}$ ) were introduced to each reactor. In the case of mixed cultures, the reactors were inoculated with two suitable strains (the components of a given mixture) in equal proportion $(1: 1)$, in a volume of $7.5 \mathrm{ml}$ each. The bacteria concentration of suspension of each introduced strain was the same $(\sim 15 \times$ $10^{8} \mathrm{cfu} / \mathrm{ml}$ ). Inoculated samples were incubated at a temperature of $26^{\circ} \mathrm{C}$ for $48 \mathrm{~h}$ (up to the stationary growth phase). Both pure and mixed cultures were 
Table 2 Bioreactors - modifications of series

\begin{tabular}{|c|c|c|c|c|c|c|}
\hline & Series "nm" & Series "pH" & Series "sm" & Series "pH+Sm” & Series "db" & Control series \\
\hline Medium & $\mathrm{KGM}^{\mathrm{a}}$ & KGM & KGM & KGM & KGM & KGM \\
\hline Biomass & + & + & + & + & $++^{\mathrm{b}}$ & - \\
\hline Dye mixture & + & + & + & + & + & + \\
\hline Addition of $\mathrm{NaOH}$ & - & When $\mathrm{pH}<4,5$ & - & When $\mathrm{pH}<4,5$ & - & - \\
\hline Addition of growth medium & - & - & $5 \mathrm{ml}$ every $48 \mathrm{~h}$ & $5 \mathrm{ml}$ every $48 \mathrm{~h}$ & - & - \\
\hline
\end{tabular}

${ }^{\mathrm{a}} \mathrm{KGM}$ - Kimura growth medium

${ }^{b}$ The sample with dead biomass for estimation of sorption

prepared at two experimental versions, which were conducted in different ways. One part of these 48-hold bacterial cultures (pure and mixed) was autoclaved $\left(121^{\circ} \mathrm{C}, 20 \mathrm{~min}\right)$ in order to obtain dead biomass which was used to estimate the sorption contribution in the decolourization process. The second part was used for decolourization studies with usage of the living biomass.

During the decolourization studies, four doses of dye mixture were introduced into each bioreactor. The first dose of dye mixture was introduced at the stationary growth phase (48-h-old cultures). For all reactors (with living and dead biomass), the initial concentration of dye mixture was $80 \mathrm{mg} / \mathrm{l}$. After decolourization of this initial dose of dye mixture, the subsequent portions of dyes were introduced in three and even four doses. Each portion was introduced after the removal of the previous portion (i.e. generally when absorbance decreased to 0.200 , which corresponded with dye concentration below $1.5 \mathrm{mg} / \mathrm{l}$ ). The next portion of dye mixture was introduced in volumes permitting an increase of mixture concentration in the reactors by $30 \mathrm{mg} / \mathrm{l}$ each time.

In reactors with the $\mathrm{pH}$ correction (" $\mathrm{pH}$ " and " $\mathrm{pH}+$ sm"), $\mathrm{pH}$ value was adjusted to between 6.0-6.8 using $0.3 \mathrm{M}$ solution of $\mathrm{NaOH}$. In reactors " $\mathrm{sm}$ " and " $\mathrm{pH}+$ sm", six-fold concentrated Kimura growth medium was used for nutrient supplementation. Portions of sterile Kimura growth medium were introduced every 48 h, at a volume of $5 \mathrm{ml}$ (this portion size corresponded to the ingredient contents in $30 \mathrm{ml}$ of standard Kimura medium). Depending on the modification, the growth medium and the solution for $\mathrm{pH}$ correction were introduced. To avoid the impact of these operations on the dye mixture concentration in each bioreactor, the volumes of the collected and introduced liquid in all reactors were identical. Appropriate volumes of sterile saline were introduced in reactors without modification in order to maintain the identical volume of mixtures.

For performance analysis, samples were collected on the first day after 1, 6 and $24 \mathrm{~h}$, and then every $24 \mathrm{~h}$ thereafter. After collection, all samples were centrifuged (5000 rpm, $10 \mathrm{~min}$ ). The dye mixture content in the resulting supernatant was measured using a spectrophotometer Hitachi U-1900 UV-Vis, at a wavelength determined experimentally, and corresponding to maximum absorbance values $(591 \mathrm{~nm})$. The absorbance results were used to determine the dye mixture content in the samples according to standard curves. Absorbance was measured before and immediately after the introduction of each additional dose of dye mixture, in order to determine the real concentration of dye in the sample.

\subsection{Ecotoxicity Evaluation}

Post-trial samples underwent ecotoxicological evaluation. Dye contaminants mainly get to the freshwater ecosystems, so for ecotoxicity tests were chosen the freshwater organisms easily cultivated. Phytotoxicity and zootoxicity tests were performed. Daphnia magna (OECD 202) was used for the evaluation of zootoxicity (the lack of movement of the test organism was considered as toxic effect). The phytotoxicity evaluation was performed according to the OECD Lemna sp. growth inhibition test no.221 (the presence of necrosis, chlorosis, fronds-colony disintegration was considered as toxic effect). All tests were performed in quadruplicate. Based on the EC50 value, the acute toxicity unit (TUa) was calculated according to the formula:

$\mathrm{TUa}=100 / \mathrm{EC} 50$

where EC50 is the effective concentration of a wastewater sample that causes $50 \%$ inhibition of tested organisms. 
Samples were classified according to ACE89/BE2/D3 Final Report Commission EC (I class, TUa $<0.4-$ nontoxic; II class, $0.4 \leq \mathrm{TUa}<1.0-$ low toxicity; III class, $1.0 \leq \mathrm{TUa}<10$ - toxic; IV class, $10 \leq \mathrm{TUa} \leq 100$ - high toxicity; and V class, TUa $>100$ - extremely toxic).

\subsection{Statistical Analysis}

The programme Statistica 5.1 (ANOVA/MANOVA test NIR) was used for statistical analysis. To verify the assumed hypothesis, a significance threshold of $p<0.05$ was chosen a priori.

\section{Results and Discussion}

\subsection{Influence of Dye Mixture Concentration on Decolourization Efficiency}

Dye mixture concentration had a significant impact on bacterial decolourization results. A concentration of dyes in solution that is too high may be toxic for microorganisms and may decrease decolourization efficiency (Pearce et al. 2003; Zabłocka-Godlewska et al. 2014, 2015). On the other hand, it has been reported that dye concentration that is too low may negatively influence the recognition of dyes by enzymes and may similarly decrease decolourization efficiency (Meerbergen et al. 2018; Pearce et al. 2003). It has been reported that dye concentration in typical textile effluents ranges between 10 and $50 \mathrm{mg} / 1$ (Karim et al. 2018).

Decolourization efficiency was comparable across all strains at a dye mixture concentration between 20 and $40 \mathrm{mg} / \mathrm{l}$ (Table 3). Increased dye concentration caused a decrease in removal efficiency across all examined strains. In samples with dye mixture concentrations from 20 to $80 \mathrm{mg} / 1$ the decolourization efficiency after $96 \mathrm{~h}$ was higher than $50 \%$ and significantly decreased below $50 \%$ in all samples with a dye mixture concentration higher than $80 \mathrm{mg} / \mathrm{l}$. Wu et al. (2009a) reported that the decolourization efficiency of particular dyes (four triphenylmethane and two azo dyes) by Pseudomonas otitidis and Shewanella oneidensis MR strains was decreased with an increase of dye concentration in the range of $10-500 \mathrm{mg} / \mathrm{l}$. The same tendency was observed by Tony et al. (2009), who studied the ability of a bacterial consortium to decolourize different concentrations (ranging from 30 to $100 \mathrm{mg} / \mathrm{l}$ ) of six azo dyes, as well as a mixture composed of a subset of four of them. Similar results were obtained by Joshi et al. (2008), Cui et al. (2012), Kalyani et al. (2009) and others. Based on the results of these concentration tests, an initial dye mixture concentration of $80 \mathrm{mg} / \mathrm{l}$ was chosen for the following decolourization studies.

\subsection{Decolourization Studies}

For the decolourization studies, a mixture of two dyes (triphenylmethane brilliant green and disazo Evans blue) was used. The process of dye removal by bacteria can be aerobic or anaerobic. The mechanisms may vary and can include a physical adsorption by the bacterial biomass (alive or dead) or an enzymatic biotransformation and/or biodegradation. The mechanism may also involve a combination of all of these processes. (Chen et al. 2010; Kuhad et al. 2012; Meerbergen et al. 2018; Ren et al. 2006; Solis et al. 2012; Srinivasan and Viraraghavan

Table 3 The results of the concentration tests

\begin{tabular}{llll}
\hline $\begin{array}{l}\text { Dye mixture } \\
\text { concentration }[\mathrm{mg} / 1]\end{array}$ & \multicolumn{2}{l}{ Bacteria strains } & \\
\cline { 2 - 4 } & $\begin{array}{l}\text { Aeromonas hydrofila }(\text { Abs37) } \\
\text { Dye mixture removal after 96 h [\%] }\end{array}$ & Citrobacter sp. (Cbs50) & Pseudomonas putida (Pzr3) \\
\hline 20 & $100.00 \pm 0.39$ & $100.00 \pm 1.12$ & $98.01 \pm 0.57$ \\
40 & $100.00 \pm 1.34$ & $96.13 \pm 2.39$ & $91.76 \pm 1.44$ \\
60 & $88.91 \pm 1.12$ & $77.00 \pm 2.54$ & $76.33 \pm 3.39$ \\
80 & $73.54 \pm 2.16$ & $51.67 \pm 2.44$ & $62.79 \pm 2.55$ \\
100 & $41.33 \pm 1.54$ & $35.63 \pm 1.06$ & $44.21 \pm 1.66$ \\
120 & $28.09 \pm 3.67$ & $21.09 \pm 2.18$ & $40.06 \pm 0.78$ \\
\hline
\end{tabular}


2010; Wang et al. 2012; Zabłocka-Godlewska et al. 2014; Zabłocka-Godlewska et al. 2015).

Decolourization studies were conducted in static conditions in fed-batch bioreactors. The strains used in the studies were: Aeromonas hydrophila and Citrobacter sp. (facultative anaerobe, Gram-negative, rod-shape, non-spore-forming, motile bacteria), and Pseudomonas putida (obligate aerobe, Gram-negative, rod-shape, non-spore-forming, motile bacteria). Citrobacter species are commonly found in aquatic environments, soil, food, and the intestinal tracts of animals and humans. Aeromonas hydrophila occurs widely in aquatic environments, sludge, and sewage. Pseudomonas putida is commonly found in soil and aquatic environments (Ren et al. 2006).

\subsubsection{Dye Mixture Removal by Pure Bacterial Culture}

During the first stage of these studies, the dye removal efficiency of pure bacterial strains was examined. All strains removed the first dose of the dye mixture $(80 \mathrm{mg} /$ 1) with high efficiency (Figs. 1, 2 and 3). Modification of the bacterial growth conditions had a significant influence on decolourization efficiency only for the third and fourth doses of dye mixture (every $30 \mathrm{mg} / \mathrm{l}$ ).
In bioreactors inoculated with the facultative anaerobe Aeromonas hydrophila (Abs37), the modification of growth conditions had a significant influence on the results of dye removal (Figs. 1 and 9A). All modifications accelerated the efficiency of dye mixture removal. In comparison with bioreactor " $\mathrm{nm}$ ", these differences were statistically significant $(p<0.05)$ (Figs. 1 and 7). The best modification was $\mathrm{pH}$ correction combined with supplementation by nutrients (" $\mathrm{pH}+\mathrm{sm}$ "), which was similar in result to $\mathrm{pH}$ correction alone ("pH"). The differences between results reached in reactors with these modifications were not statistically significant (ANOVA/MANOVA test NIR $p>0.05$ ). In previous research, $\mathrm{pH}$ value was the most important factor in determining the growth of bacteria biomass, enzymatic activity, possibilities of sorption of dyes by biomass, and bioavailability of dyes as a carbon source (Kodam et al. 2005; Solis et al. 2012). Chen et al. (2003) reported the positive impact of such factors including the static conditions, $\mathrm{pH}$ correction, and supplementation with nutrients (especially glucose and yeast extract) on the decolourization potential of Aeromonas hydrophila. All these factors resulted in an increased removal efficiency of azo RED RBN and other complicated dye mixtures (RED RBN and 23 other different azo and anthraquinone dyes). It is worth emphasizing that yeast

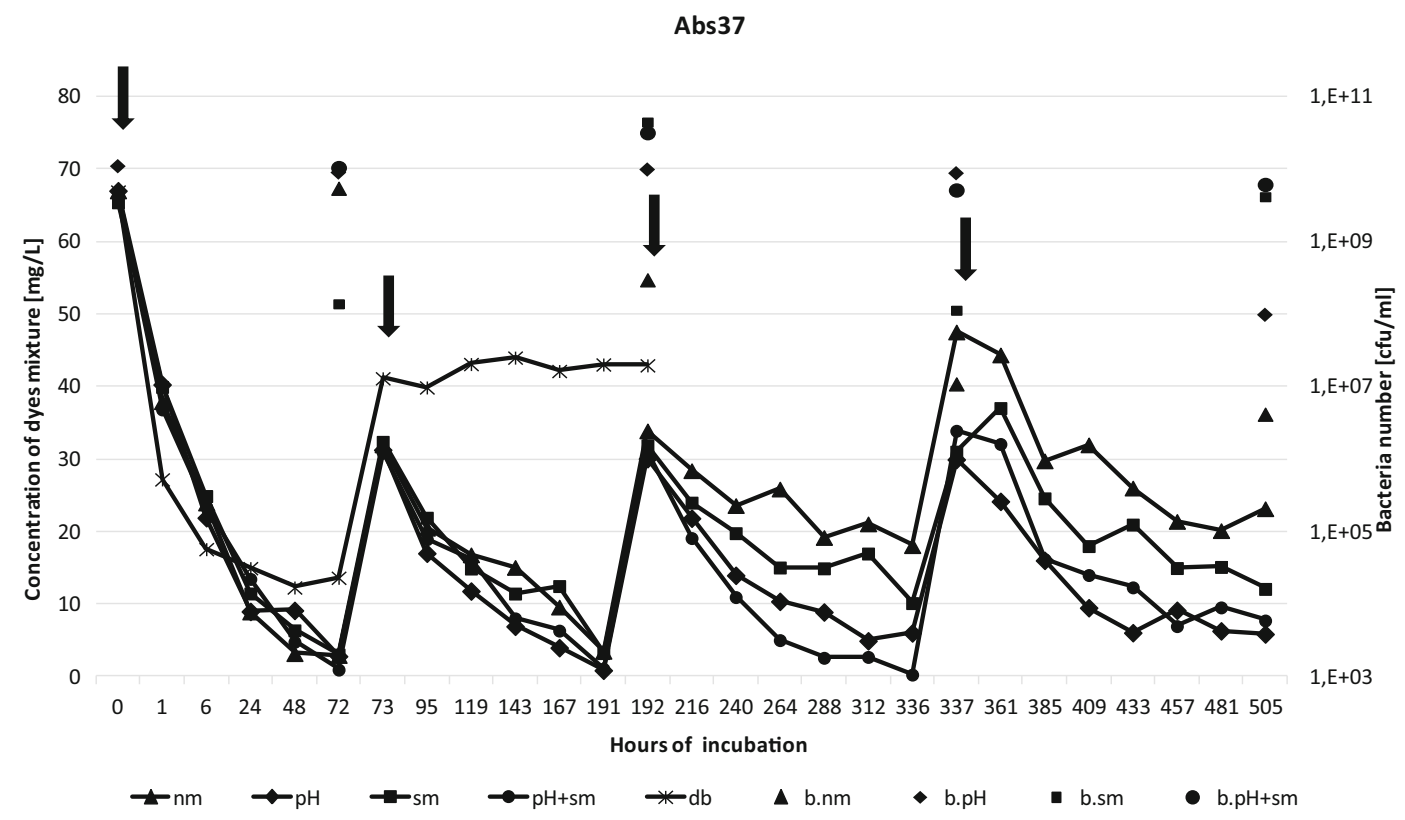

Fig. 1 Decolourization of dye mixture by Aeromonas hydrophila (Abs37). The introduction of the next doses of dyes are marked by the arrows. Abbreviations used for certain reactors: nm, no modification; $\mathrm{pH}, \mathrm{pH}$ value correction; sm, supplementation with

nutrients; $\mathrm{pH}+\mathrm{sm}, \mathrm{pH}$ correction combined with supplementation with nutrients; $\mathrm{db}$, dead biomass; b. ..., bacteria number in certain sample (nm, $\mathrm{pH}, \mathrm{sm}$, or $\mathrm{pH}+\mathrm{sm})$ ) 


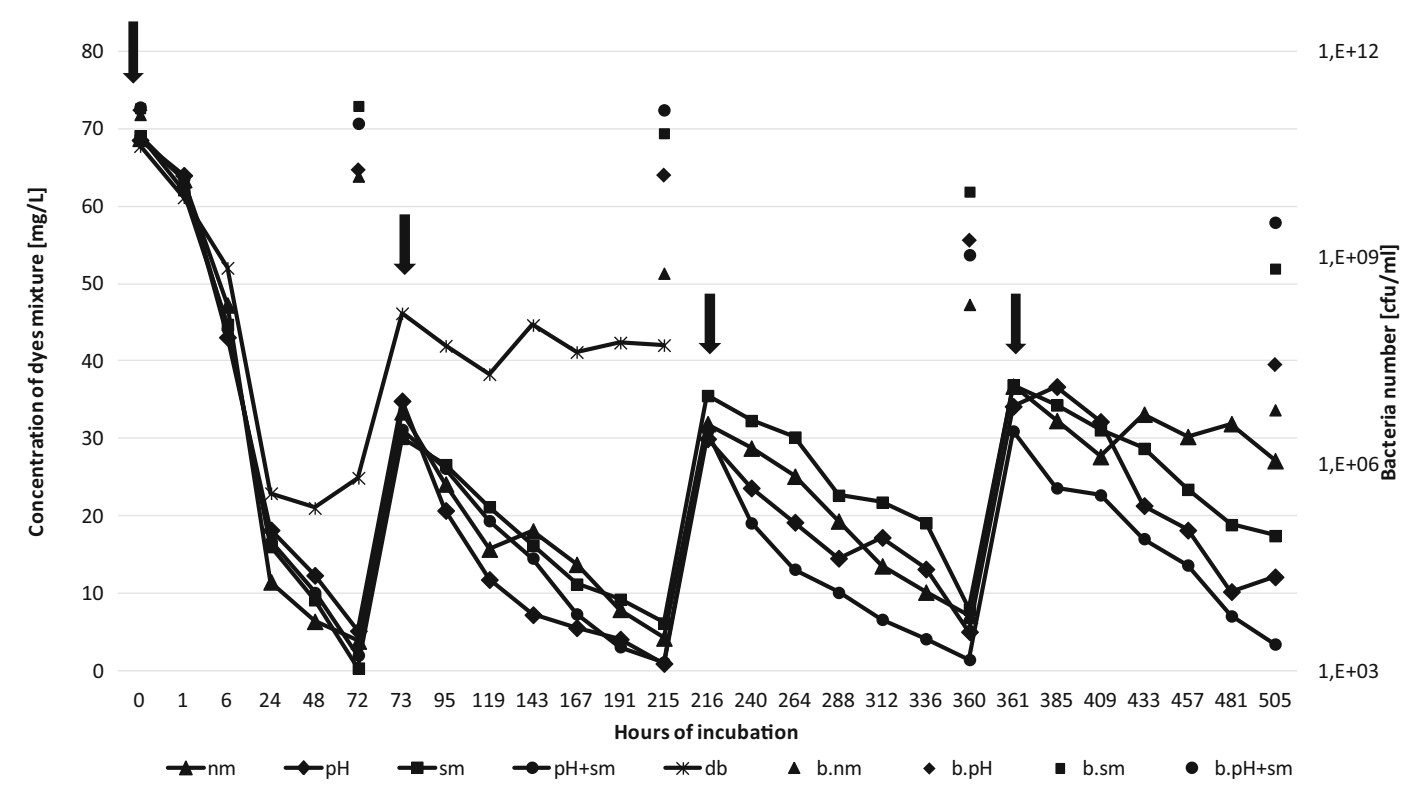

Fig. 2 Decolourization of dye mixture by Citrobacter sp. (Cbs50). The introduction of the next doses of dyes are marked by the arrows. Abbreviations used for certain reactors: nm, no modification; $\mathrm{pH}, \mathrm{pH}$ value correction; sm, supplementation with nutrients; $\mathrm{pH}+\mathrm{sm}, \mathrm{pH}$ correction combined with supplementation with nutrients; $\mathrm{db}$, dead biomass; b. ..., bacteria number in certain sample (nm, $\mathrm{pH}, \mathrm{sm}$, or $\mathrm{pH}+\mathrm{sm})$ )

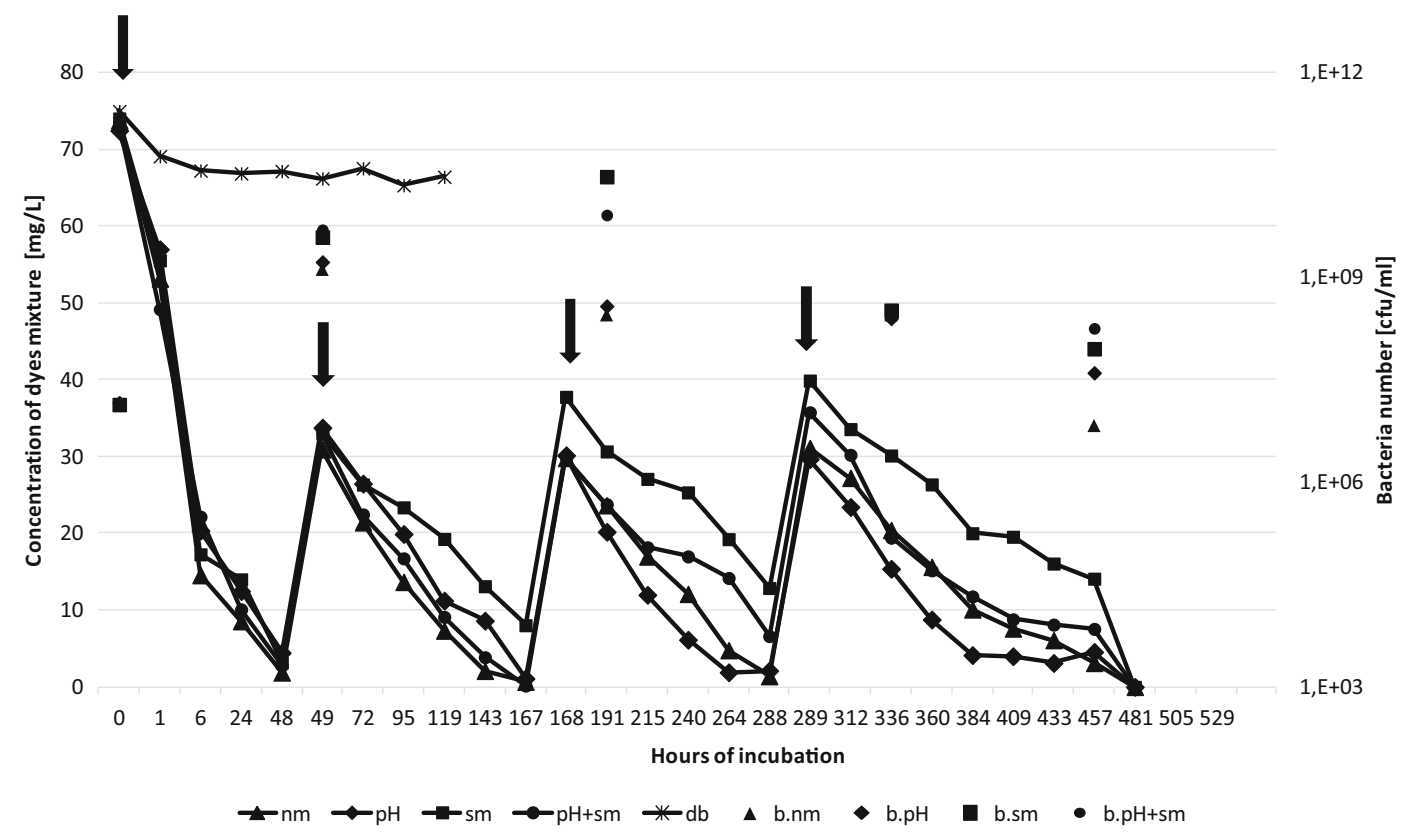

Fig. 3 Decolourization of dye mixture by Pseudomonas putida. (Pzr3). The introduction of the next doses of dyes are marked by the arrows. Abbreviations used for certain reactors: nm, no modification; $\mathrm{pH}, \mathrm{pH}$ value correction; sm, supplementation with nutrients; $\mathrm{pH}+\mathrm{sm}, \mathrm{pH}$ correction combined with supplementation with nutrients; $\mathrm{db}$, dead biomass; b. ..., bacteria number in certain sample (nm, $\mathrm{pH}, \mathrm{sm}$, or $\mathrm{pH}+\mathrm{sm})$ ) 
extract (the growth medium component used) is considered essential to the regeneration of important factors such as NADH, which acts as an electron donor for the reduction of dye bonds. Rajee and Patterson (2011) showed that the highest efficiency of decolourization of orange MR by Micrococcus sp. (80\%) was reached when $\mathrm{pH}=6$. A decrease in $\mathrm{pH}$ value to 4 , as well as an increase to 10 , resulted in a decrease in decolourization efficiency (65\% and $40 \%$, respectively). It has been reported that $\mathrm{pH}$ values in the range of 5 to 7 had a positive impact on decolourization processes, accelerating the efficiency by up to 2.5 times (Chang et al. 2001). The impact of $\mathrm{pH}$ value on decolourization efficiency was shown also by Chang et al. (2001), Meerbergen et al. (2018), Sawhney and Kumar (2011) and others. The $\mathrm{pH}$ value in bioreactors " $\mathrm{pH}$ " and " $\mathrm{pH}+\mathrm{sm}$ " fluctuated between 4.0 and 6.2 , and were higher than in bioreactors " $\mathrm{nm}$ " and "sm" (Table 4). This likely influenced the higher decolourization efficiency in these bioreactors.

The sorption test results indicate that the physical sorption of dye may be playing a role in dye removal. However, the appearance of new peaks in the UV-VIS analyses points to the presence of new metabolites and the participation of biotransformation in the decolourization processes (Fig. 9A). The decolourization of dyes by bacteria may be due to sorption on biomass and/or biodegradation (Meerbergen et al. 2018; Singh and Singh 2017). In the case of the sorption of dyes, the comparison of the peaks between UV-VIS scans, before and after sorption, showed a decrease approximately in proportion to each other. Whereas in case of the biodegradation, the major visible peaks may decrease or disappear completely, and one or more new peaks may appear. The newly appeared peaks in the UV-VIS analysis, which are detected in different wavelength ranges, indicate the newly formed metabolites (Chen et al. 2003; Meerbergen et al. 2018; Modi et al. 2010; Moosvi et al. 2005; Singh and Singh
2017). Because of the adsorption of dyes, the bacterial cells may become deeply coloured. The biodegradation of these dyes leads to a return to the original colour of the biomass. Such observations indicate that in the case of the Abs37 strain, biotransformation processes were the main mechanism and were supported by sorption at the first stage of the decolourization process. The lack of dyed biomass of Aeromonas hydrophila, which retain their natural colour after efficient decolourization processes, was also observed by Ren et al. (2006). This indicates the occurrence of biological degradation processes. Similar observations were reported in other studies (Karim et al. 2018; Meerbergen et al. 2018).

The newly formed peaks visible in the UV-VIS scans (observed in the wavelength range 365-388 nm) indicated the formation of different metabolites during the biotransformation processes in the bioreactors with different growth conditions (Fig. 9A). Modifications influenced the rate and the direction of these biotransformation processes. Enzymatic processes may lead to the complete degradation of dyes, which is the most desired outcome. However, biotransformation processes may also lead to the formation of toxic metabolites. The efficiency of the process, mechanisms involved, and the possibility of toxic metabolite formation all depends on what bacterial strains are used, the process conditions, the structure and concentration of dyes, and the composition of the dye mixture (Ali 2010; Kuhad et al. 2012; Meerbergen et al. 2018; Przystaś et al. 2012, 2015; Saratale et al. 2011; Solis et al. 2012; Srinivasan and Viraraghavan 2010; Zabłocka-Godlewska et al. 2014, 2015). It should be emphasized that in the bioreactors "pH" and "pH+sm" inoculated with the Abs37, dyes removal was most efficient, however the supplementation with nutrients combined with $\mathrm{pH}$ correction lead to an increase of the concentration of metabolites (high peak with max. absorbance in wavelength = $366 \mathrm{~nm}$ ) (Figs. 1, 7 and 9A). Changes of the growth conditions in the bioreactors positively influenced the

Table 4 The changes of the $\mathrm{pH}$ value in bioreactors during the studies (grey spaces - $\mathrm{pH}$ value "before-after" correction)

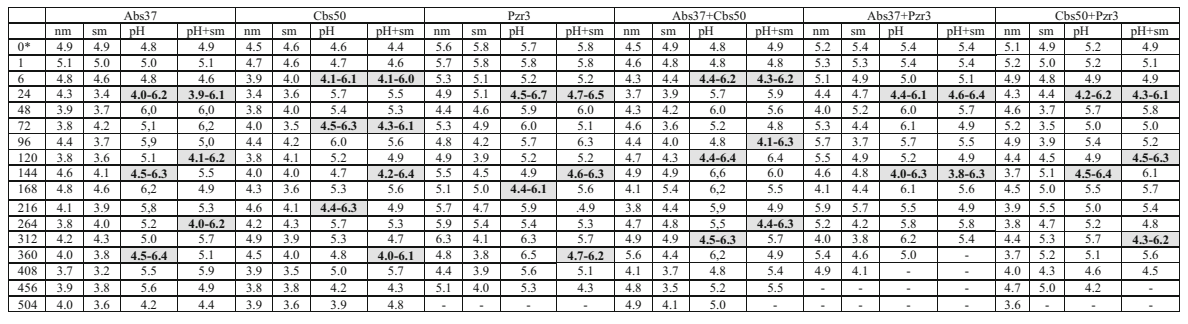


growth of bacteria number [cfu/ml], especially in the reactor with $\mathrm{pH}$ correction and $\mathrm{pH}$ correction combined with nutrient supplementation, which partially corresponded with the resulting dye removal (Fig. 1). Ren et al. (2006) reported the high decolourization efficiency of Aeromonas hydrophila. The strain was able to decolourize triphenylmethane, azo and anthraquinone dyes in static conditions.

The ability of Citrobacter sp. to efficiently decolourize triphenylmethane and azo dyes in static conditions was documented in An et al. (2002) and Jang et al. (2005). They reported that the enzyme triphenylmethane reductase (TMR) was responsible for the high decolourization of triphenylmethane dyes (even in high concentrations ranging from 5 to $2000 \mu \mathrm{M}$ ) by Citrobacter sp. strain KCTC 18061P. In our experiments, the strain Citrobacter sp. (Cbs50) was used. Modifications of the growth conditions in the reactors inoculated with the facultative anaerobe Citrobacter sp. (Cbs50) variously influenced the decolourization results (Figs. 2, 7 and 9B). Differences were visible after the introduction of the third and fourth doses of the dye mixture. Kruscal-Wallis with post-hoc (NIR) test were used to confirm the differences between particular batches. An increase in the process efficiency (in comparison with the batch "nm") was observed in all reactors, but this difference was only statistically significant in the reactor " $\mathrm{pH}+\mathrm{sm}$ " $(p<0.05)$. The results of the sorption test indicate that the process is using both sorption and biotransformation. The lack of newly formed peaks in the UV-VIS scans in the samples "nm" and "sm", and small new peaks in the samples " $\mathrm{pH}$ " and "pH+sm" indicate the lack or low concentration of metabolites, and suggest the complete or nearly complete degradation of the dyes and metabolites formed during biotransformations processes (Fig. 9B).

Another confirmation of the biological character of processes with Cbs50 strain was the retention of the natural colour of bacteria biomass after the decolourization process (despite the deeply dyed biomass observed at the beginning of process). This suggests that the dye mixture removal was mainly an enzymatic process and the adsorption of dyes may play a role during the first stage of the process by catching the dyes on the surface of the bacterial cells. Similar results have been obtained by other authors (Karim et al. 2018; Meerbergen et al. 2018). All modifications of growth conditions stimulated the growth of bacteria biomass, which was greater in bioreactors with supplementation by nutrients (“sm' and 'pH+sm”). However, this corresponded only partially with the decolourization efficiency in these reactors (Fig. 2).

Bacteria strains which present the broad metabolic capabilities are especially desirable at cleaning technologies such as activated sludge. They have the abilities to switch from one carbon source to another, what is very advantageous feature. It is reported that bacteria from genera Citrobacter have the capabilities to degrade efficiently a various xenobiotics with complex structure such as for example PAH's or TNT (Liao et al. 2018; Ibrahim 2018).

The aerobic strain Pseudomonas putida (Pzr3) removed all doses of introduced dye mixture in the shortest period of time (Fig. 3). In comparison with other studied strains, times were shorter than $72 \mathrm{~h}$ (Figs. 1, 2, 3 and 7). The high decolourization potential of P. putida was reported by Silveira et al. (2009). The results of the plate test show that the strain was able to grow on the plates with the presence of 9 of 14 different textile dyes in concentration $1 \mathrm{~g} / \mathrm{l}$ as a sole carbon source. Decolourization of dyes $(50 \mathrm{mg} / \mathrm{l})$ in liquid cultures show that after $48 \mathrm{~h}, P$. putida was able to remove 10 of the 14 tested dyes with different efficiency (ranging from 25 to $72 \%$ ) (Silveira et al. 2009). Sneha et al. (2013) reported that the aerobic bacteria P. putida removed different dyes (crystal violet, safranine, tryptan blue) more efficiently in static than dynamic conditions. The results reached in reactors inoculated with Pzr3 were completely different from those obtained with the strains Abs37 and Cbs50. A slight increase of decolourization efficiency (not statistically significant $p>0.05$ ) was observed only in the reactor with $\mathrm{pH}$ correction. The modification of growth conditions connected with nutrient supplementation ("sm" and " $\mathrm{pH}+$ sm") caused a decrease in decolourization efficiency in comparison with the reactor without modifications ("nm") (Figs. 3, 7 and 8). In the bioreactor supplemented by nutrients this negative impact was statistically significant ( $p=0.0063$ ). The values of $p<0.05$ calculated when comparing the reactor "sm" with the reactors " $\mathrm{pH}$ " and " $\mathrm{pH}+\mathrm{sm}$ " indicate that, in the case of the strain Pzr3, introducing nutrients significantly decreases decolourization efficiency. The presence of nutrients likely decreased the bacterial interest in the dye mixture.

Decolourization of synthetic dyes strongly depends on the presence of bioavailable co-substrates. Only a few studies have been successful in isolating the bacterial strains capable of using dyes as a sole source of 
carbon (Karim et al. 2018; Meerbergen et al. 2018; Solis et al. 2012). It has also been reported that growth medium composition is critical to the efficiency of decolourization by microorganisms. However, in some cases, additional carbon sources may repress the decolourization processes. This may be due to the repression of gene expression responsible for the biosynthesis of enzymes required for utilization of xenobiotics as carbon sources (Jadhav et al. 2008; Karim et al. 2018; Meerbergen et al. 2018; Solis et al. 2012). Mohana et al. (2008) showed that supplementation of reaction solution by co-substrates such as glucose and yeast extract in $\mathrm{w} / \mathrm{v}$ concentrations of $0.15 \%$ and $0.08 \%$, respectively, may decrease decolourization efficiency. Junnarkar et al. (2006) reported that exceeding a starch concentration of $0.6 \mathrm{~g} \mathrm{~L}^{-1}$ did not further increase decolourization efficiency. Saratale et al. (2009) pointed out that the presence of various carbon and nitrogen sources in the growth medium might have a stimulatory or inhibitory effect on the enzyme systems involved in decolourization.

The appearance of new peaks in the UV-VIS analyses (peaks with max. absorbance in wavelength range 378$395 \mathrm{~nm}$ ) point to the presence of new metabolites, which confirms the enzymatic mechanisms of decolourization by Pzr3 (Fig. 9C). The highest new peaks were observed in the sample from the reactor without modifications (two high peaks with max. absorbance in wavelength $=378$ and $=395 \mathrm{~nm}$ ). Therefore, it can be concluded that in the case of Pzr3, modifications increased the degradation of metabolites formed during the dye removal processes, despite having no impact on decolourization efficiency. The results obtained in the sorption studies excluded the role of sorption in dye removal by Pzr3 and indicated that in the case of this strain biodegradation or/and biotransformation processes were more important. The promotion of the growth of Pzr3 biomass in the bioreactors supplemented with the bioavailable nutrients did not increase decolourization efficiency (Fig. 3).

There are a lot of reports which confirm that bacteria from genera Pseudomonas have also the ability to degrade efficiently the wide spectrum of others complex xenobiotics, for example, PAHs, pesticides, PCBs (Imam et al. 2019; Ramadass et al. 2018; Salimizadeh et al. 2018; Tandlich et al. 2001; Zheng et al. 2018). Such properties make these bacteria the promising candidates for use at the various cleaning technologies.
All modifications of growth conditions positively influenced bacterial growth and maintained higher bacterial vitality in the bioreactors, which in general affected the decolourization results (with the exception of Pzr3).

In all reactors, the initial concentration of the dye mixture was $80 \mathrm{mg} / \mathrm{l}$. Despite the lower load of dyes in each subsequent doses $(30 \mathrm{mg} / \mathrm{l})$, the time needed for dye removal in all reactors was longer. There may be a few reasons of this phenomenon.

Sorption (even in the case of the strain Pzr3 with low sorption capacity) may be the first stage of dye removal, causing a relatively fast decrease of dye concentration in solution. During the next stage, the absorbed dyes may undergo the processes of biotransformation. This stage requires more time than physical sorption on the surface of bacterial cells and depends on various factors such as temperature, $\mathrm{pH}$, redox potential, dye structure and concentration, and the properties of the bacteria. (Jang et al. 2005; Srinivasan and Viraraghavan 2010; Vijayaraghavan and Yun 2008; Wu et al. 2009a; Zabłocka-Godlewska et al. 2015).

In the discussed case, during the removal of the first dose, the bacterial biomass was probably quickly saturated with dyes. This could extend the time of removal of the second and subsequent doses of the dye mixture. The saturated biomass was unable to adsorb and transform the next molecules of dye until those from the first dose were gradually degraded, freeing places for the next molecules. In this way the biomass was probably undergoing the continuous regeneration of sorption capacities which might elongate the time needed for decolourization of next doses of dyes.

These decolourization studies were conducted in static conditions in fed-batch bioreactors. For this kind of reactor, it is typical that at deeper levels of reaction solution, higher oxygen deficit occurs. Biotransformation of azo dyes in such conditions leads to formation and accumulation of toxic aromatic amines (Chang et al. 2004; Pandey et al. 2007; Saratale et al. 2011; Wang et al. 2009). Additionally, during the decolourization processes conducted in fed-batch reactors metabolites are accumulated, growth conditions worsen, and the microbiocenosis get older with time. The slowdown of the final stages of decolourization may also be connected with these changes. Differences were more significant after each successive dose of dyes introduced into the bioreactor. 


\subsubsection{Dye Mixture Removal by Mixed Bacterial Cultures}

The metabolic capabilities of a single bacterial strain are limited by an enzymatic suite which is specific for a given strain. The limitation of possibilities of removal of structurally different dyes occurring in coloured sewages, may lead to incomplete decomposition of dyes and the formation of toxic metabolites (Chan et al. 2011; Joshi et al. 2010; Phugare et al. 2011; Saratale et al. 2009; Saratale et al. 2011; Waghmode et al. 2011). Wider metabolic capabilities are presented by mixed bacterial cultures. Proper selection of bacterial strains and preparation of mixed cultures should guarantee an increase of decolourization efficiency for a diverse group of substrates. In mixed microbiocenosis, the occurrence of metabolic synergistic effects is possible. The complex microbiocenosis should be able to attack the dyes molecules in different positions and have broader possibilities for the further decomposition of metabolites, which are sometimes more toxic than the parent substances (Chan et al. 2011; Joshi et al. 2010; Phugare et al. 2011; Saratale et al. 2009; Saratale et al. 2011; Waghmode et al. 2011). A few reports pointed out that the preparation of mixed cultures, made up of strains showing high decolourization ability, may increase efficiency and reduce the process time (Cui et al. 2012; Jadhav et al. 2010; Joshi et al. 2008; Sharma et al. 2004).

In a given ecosystem, the similar ecological needs of different species of microorganisms lead to the creation of various mechanisms of competition between them. One of these is antagonistic relations (Alexander 2013). In the second stage of the decolourization studies, mixed bacterial cultures were used. Antagonistic plate tests showed a lack of negative interactions between the studied microorganisms, allowing for the use of all tested strains in the preparation of mixed cultures.

The second stage of the decolourization studies was conducted using three mixtures of bacterial strains: Abs37+Cbs50, Abs37+Pzr3 and Cbs50+Pzr3.

In general, the usage of the two-strain mixed cultures in the decolourization process resulted in an increase of dye removal efficiency, but differences were not always statistically significant (Figs. 4, 5 and 6). In some cases, a reduction of time needed for dye mixture removal was observed. Karim et al. (2018) reported that a prepared bacterial consortium (mixture of five isolates) was much more efficient than monocultures in decolourizing five single dyes as well as a mixture of those dyes, indicating the possibility of the use of this consortium for cost- effective removal of diverse dyes from effluents. Jadhav et al. (2010) presented the results of decolourization of textile effluents by strains SUK1, LBC2 and LBC3 belonging to a phylogenetic branch of Pseudomonas sp. Strains were used individually and as a mixture (DAS). Higher decolourization efficiency was observed for the consortium as compared to individual bacterial strains, which may be due to the enhanced effect of coordinated metabolic interactions.

As was the case with bacterial monocultures, in reactors with mixed cultures, the influence of modifications on dye removal was only observed after the introduction of the third and fourth dose of dye. All modifications of the growth conditions positively influenced decolourization efficiency of the used bacterial mixtures (Figs. 4, 5 and 6).

The first studied mixture was composed of two facultative anaerobic bacterial strains Abs37+Cbs50 (Fig. 4). The removal of the second portion of dye was slowed down in the case of the strain mixture, in comparison with the strain Abs37 when used as monoculture. The next stages of the process were more efficient in the case of the bacterial mixture (Figs. 1, 2 and 4). All modifications accelerated the efficiency of dye mixture removal and differences were statistically significant (ANOVA/MANOVA test NIR $p<0.05$ ). The best results of dye removal were reached in the reactor " $\mathrm{pH}+$ sm", similar to when Abs37 and Cbs50 were used as monocultures. The differences between decolourization efficiency in bioreactor " $\mathrm{pH}+\mathrm{sm}$ " and bioreactors with modifications " $\mathrm{pH}$ " and "sm" were statistically significant ( $p=0.037$ and $p=0.041$, respectively).

As mentioned previously, additional carbon and nitrogen sources, and a $\mathrm{pH}$ value in the range of 5 to 7 , generally have a positive influence on decolourization efficiency (Chen et al. 2003; Meerbergen et al. 2018; Moosvi et al. 2005; Rajee and Patterson 2011; Sawhney and Kumar 2011; Solis et al. 2012).

The results reached in the bioreactor " $\mathrm{pH}$ " were comparable with the results reached in the bioreactor "sm". While in the case of strains Abs37 and Cbs50 used as monocultures, the $\mathrm{pH}$ correction influenced dye removal more positively than the supplementation alone (Figs. 1, 2, 7 and 8). These results suggest the occurrence of some kind of relationship or collaboration between strains in mixed cultures in the decomposition of substrates. The sorption test results indicate that the physical sorption of dye may be playing a role in dye removal. The bacterial mixture had worse adsorption 
Abs37+Cbs50

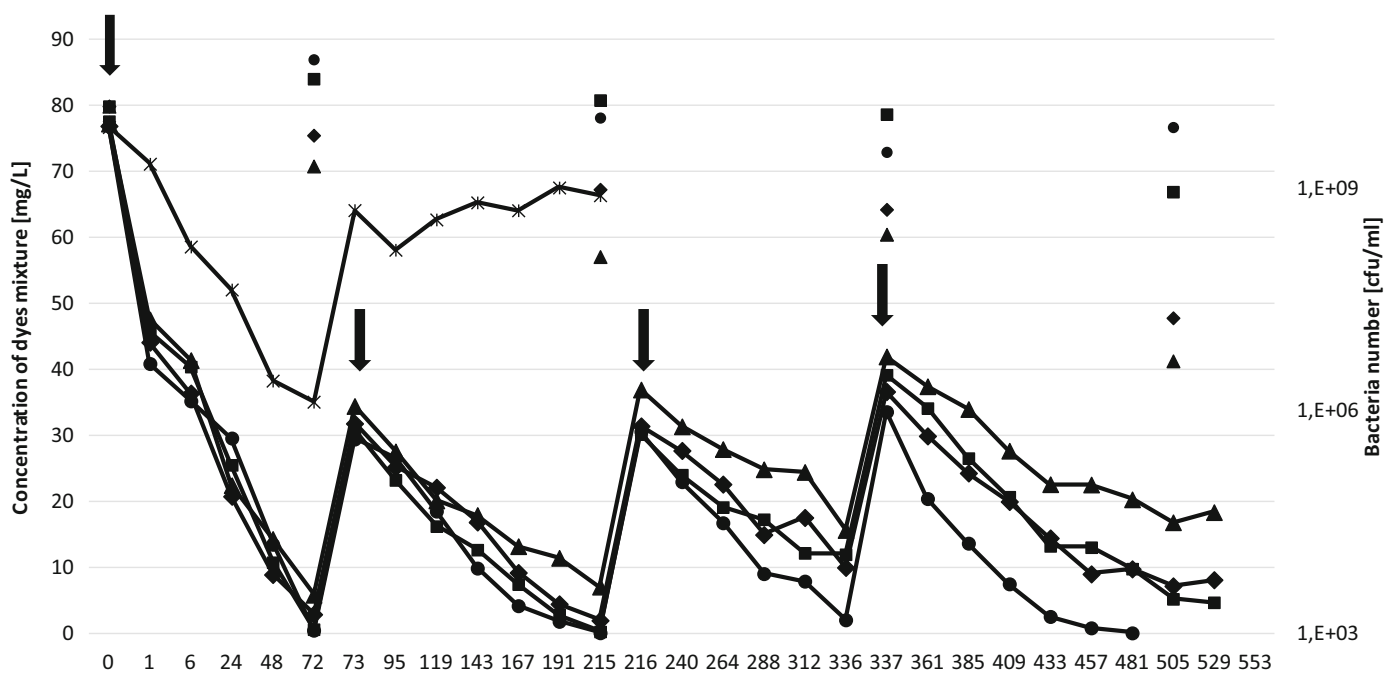

Hours of incubation

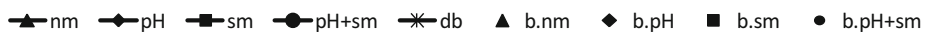

Fig. 4 Decolourization of dye mixture by mixed bacterial culture of Aeromonas hydrophila and Citrobacter sp. (Abs37+Cbs50). The introduction of the next doses of dyes are marked by the arrows. Abbreviations used for certain reactors: nm, no modification; $\mathrm{pH}, \mathrm{pH}$ value correction; sm, supplementation with nutrients; $\mathrm{pH}+\mathrm{sm}, \mathrm{pH}$ correction combined with supplementation with nutrients; $\mathrm{db}$, dead biomass; b. ..., bacteria number in certain sample (nm, $\mathrm{pH}, \mathrm{sm}$, or $\mathrm{pH}+\mathrm{sm})$ )

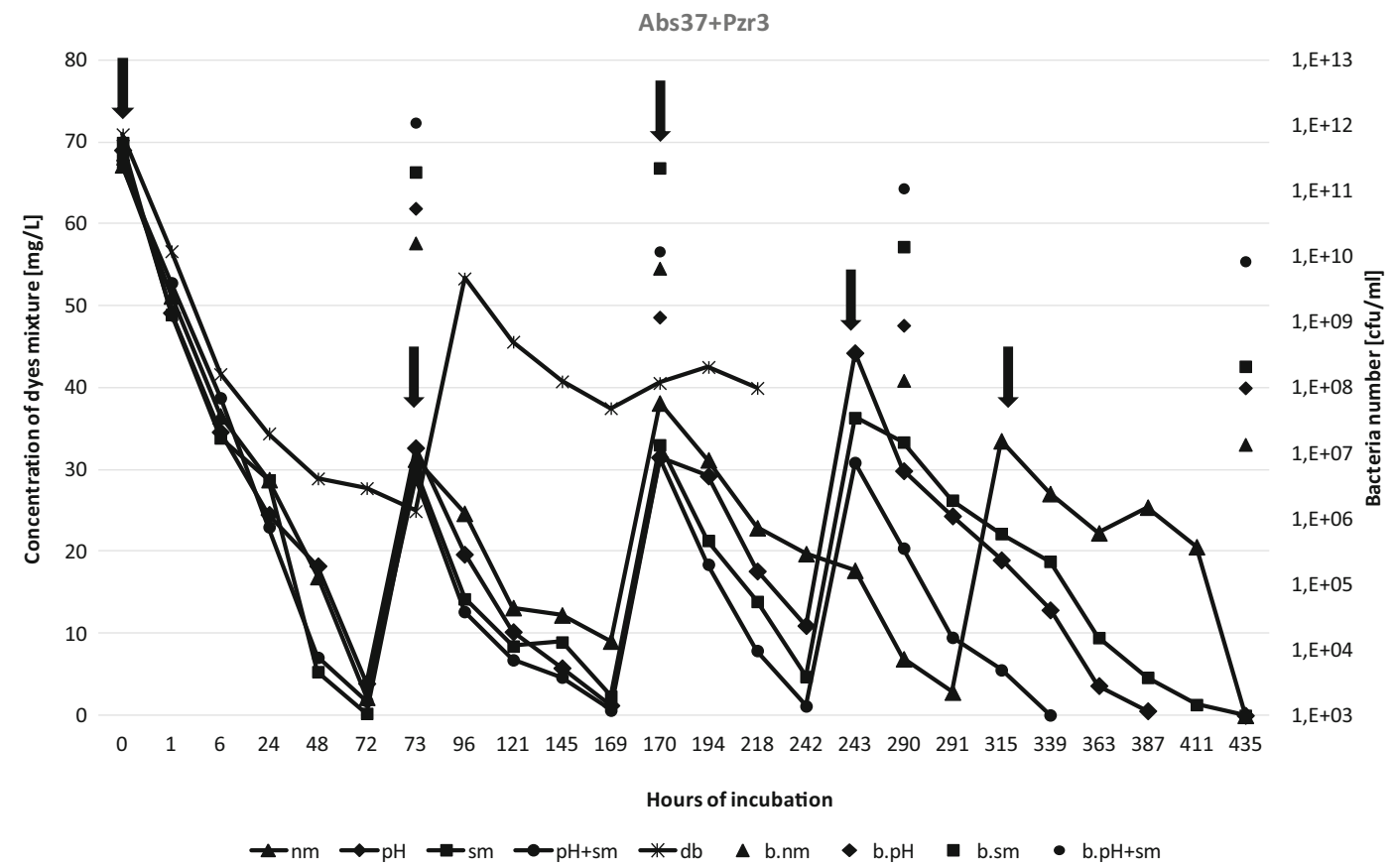

Fig. 5 Decolourization of dye mixture by mixed bacterial culture of Aeromonas hydrophila and Pseudomonas putida (Abs37+Pzr3). The introduction of the next doses of dyes are marked by the arrows. Abbreviations used for certain reactors: $\mathrm{nm}$, no modification; $\mathrm{pH}, \mathrm{pH}$ value correction; sm, supplementation with nutrients; $\mathrm{pH}+\mathrm{sm}$, $\mathrm{pH}$ correction combined with supplementation with nutrients; $d b$, dead biomass; b. ..., bacteria number in certain sample (nm, $\mathrm{pH}, \mathrm{sm}$, or $\mathrm{pH}+\mathrm{sm}))$ 


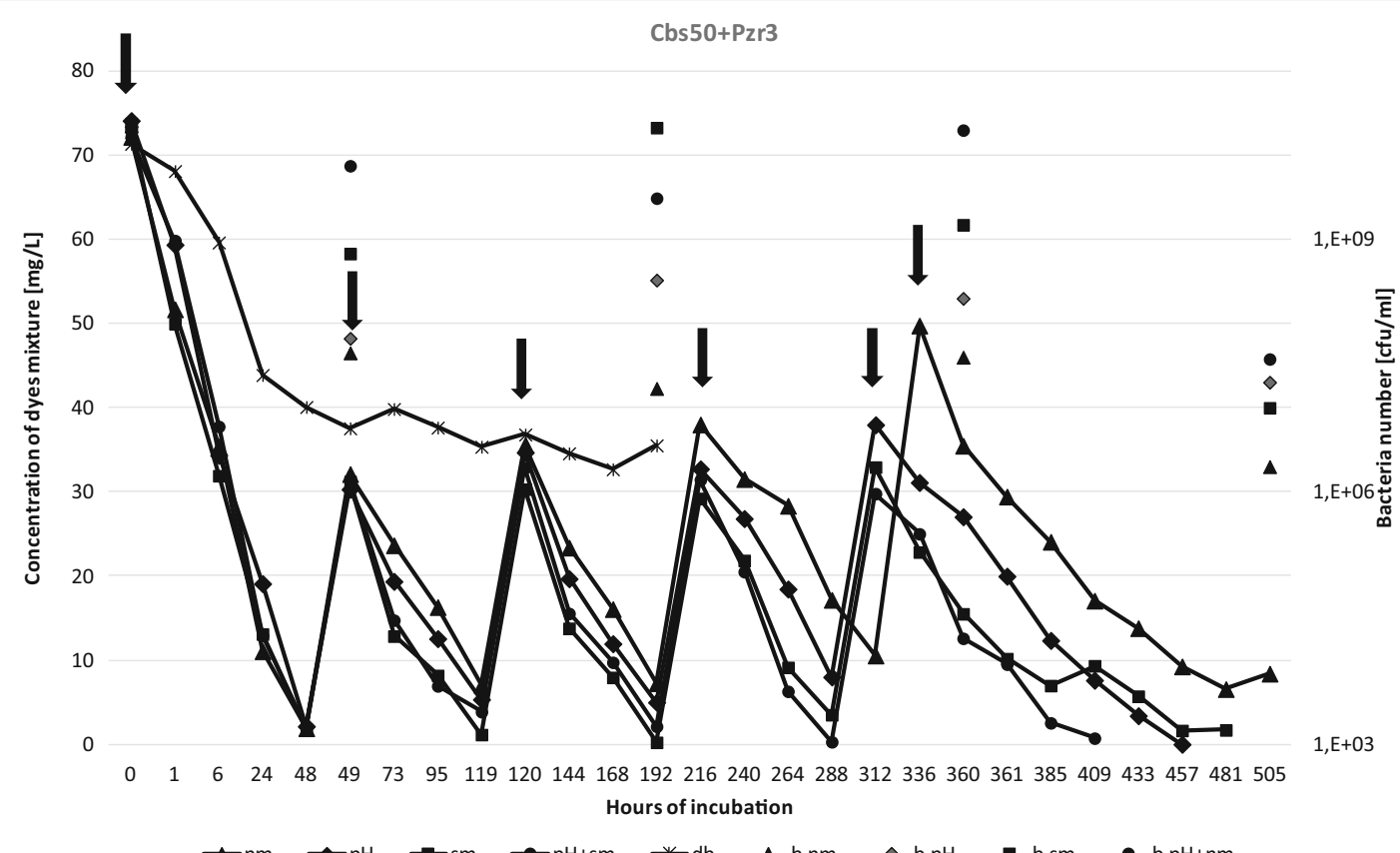

Fig. 6 Decolourization of dye mixture by mixed bacterial culture of Citrobacter sp.and Pseudomonas putida (Cbs50+Pzr3). The introduction of the next doses of dyes are marked by the arrows. Abbreviations used for certain reactors: $\mathrm{nm}$, no modification; $\mathrm{pH}$,

$\mathrm{pH}$ value correction; sm, supplementation with nutrients; $\mathrm{pH}+\mathrm{sm}$, $\mathrm{pH}$ correction combined with supplementation with nutrients; $\mathrm{db}$, dead biomass; b. ..., bacteria number in certain sample (nm, $\mathrm{pH}$, $\mathrm{sm}$, or $\mathrm{pH}+\mathrm{sm})$ )

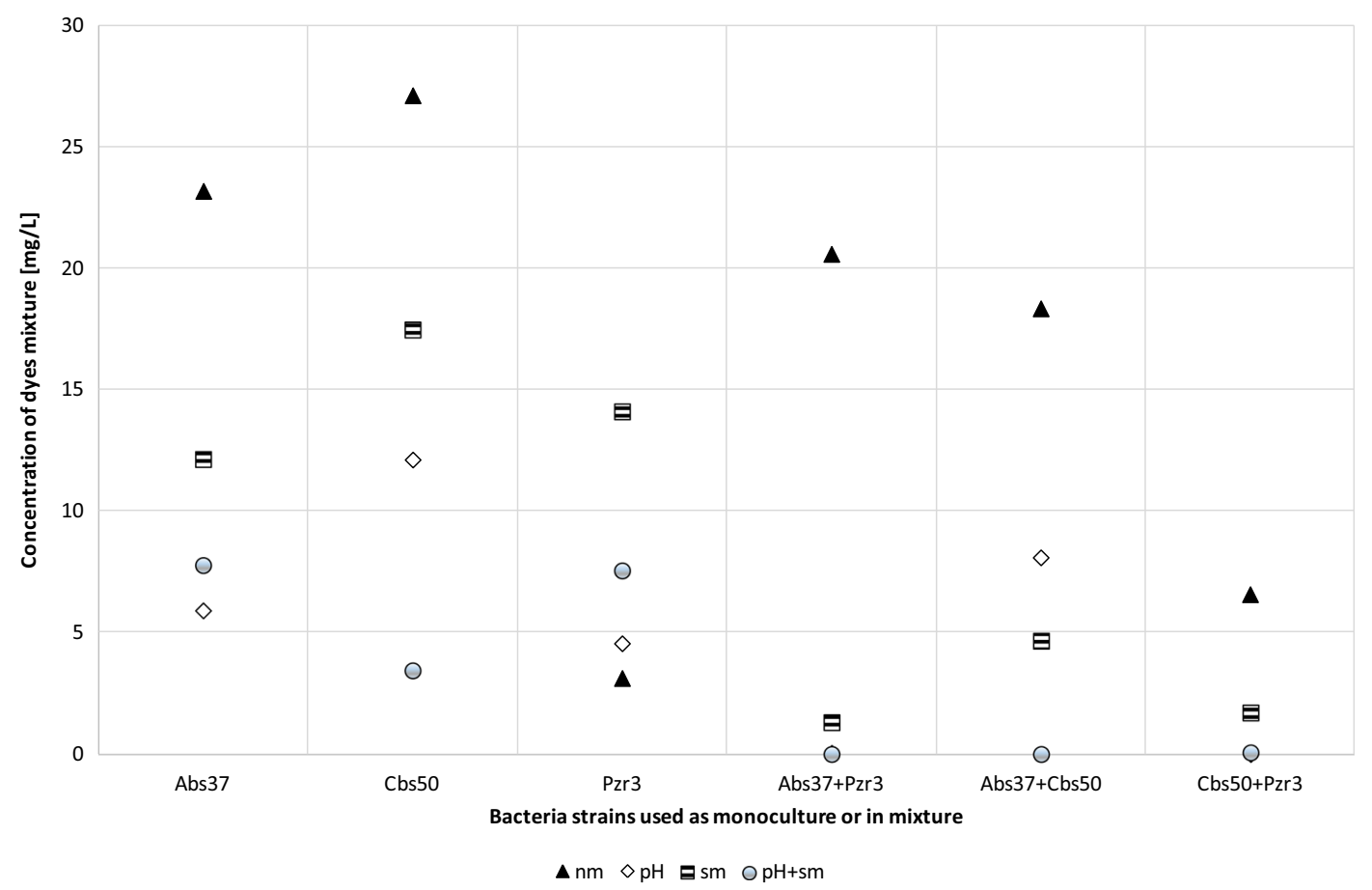

Fig. 7 The final residuals of dye mixture in reactors after decolourization of their four doses by pure and mixed bacterial cultures (nm, no modification; $\mathrm{pH}, \mathrm{pH}$ value correction; sm, supplementation with nutrients; $\mathrm{pH}+\mathrm{sm}, \mathrm{pH}$ correction combined with supplementation with nutrients) 


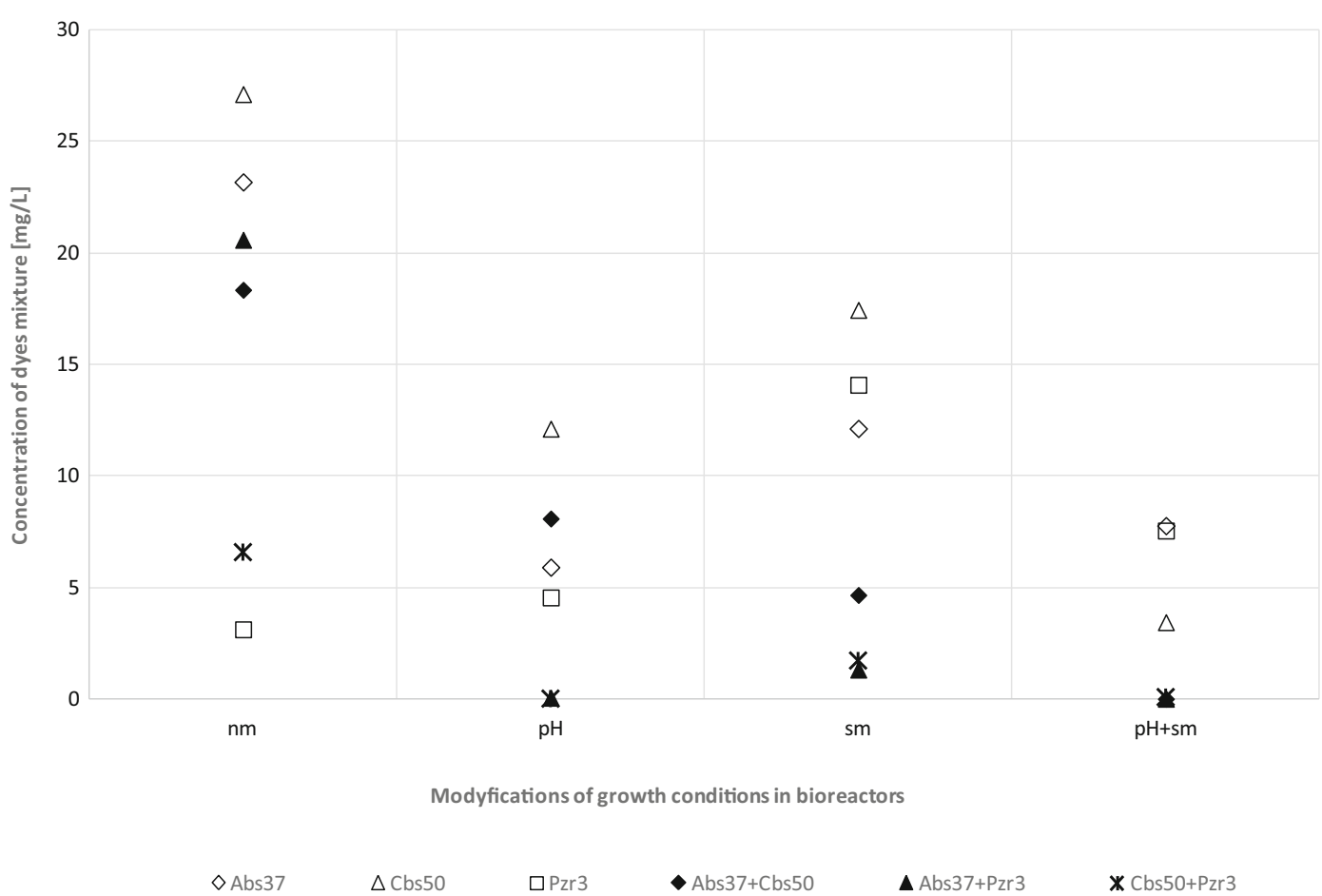

Fig. 8 The final residuals of dye mixture in reactors after decolorization of all doses of the dye mixture by pure and mixed bacterial cultures depending on the growth conditions (nm, no

properties than each component of this mixture individually. Sorption capacity depends on the structure of the cell wall, the presence of functional groups, and the presence of an outer surface layer of exopolysaccharides (Kuhad et al. 2012; Srinivasan and Viraraghavan 2010; Vijayaraghavan and Yun 2008). This changeable feature depends on, among other things, growth conditions (e.g. $\mathrm{pH}$ value). In mixed cultures, the life conditions are different than in monocultures, which also might impact the composition of the cell wall, and finally the sorption properties of each strain.

The appearance of new peaks in the UV-VIS analyses (connected with the presence of new metabolites) and the retention of the natural colour of the bacterial mixture biomass after the decolourization process suggest that dye mixture removal was mainly an enzymatic process which has also been suggested by other authors (Meerbergen et al. 2018). As was mentioned above, adsorption of dyes may play a role during the first stage of the process by catching dyes on the surface of the bacteria cells and making contact with the enzymes or electron carriers located in outer cell membrane easier (Jang et al. 2005; Wang et al. 2012; Wu et al. 2009a). Based on the UV-VIS scans there are visible qualitative modification; $\mathrm{pH}, \mathrm{pH}$ value correction; $\mathrm{sm}$, supplementation with nutrients; $\mathrm{pH}+\mathrm{sm}, \mathrm{pH}$ correction combined with supplementation with nutrients)

and quantitative differences in metabolite occurrence in post-process solutions from bioreactors inoculated with bacterial monocultures and mixtures (Fig. 9A, B, D). That such differences depend on growth condition was also observed by (Meerbergen et al. 2018). Changes in the growth conditions in the bioreactors positively influenced the number of bacteria, especially in the reactor "pH+sm" and "sm" (Fig. 4).

The second studied mixture of bacterial strains was the composition of facultative anaerobic strain Aeromonas hydrophila with obligate aerobic strain Pseudomonas putida (Abs37 + Pzr3) (Fig. 5). The monoculture of strain Pzr3 removed the dye mixture in the shortest time in comparison with the other pure cultures, but the modifications did not have a positive influence on decolourization efficiency (Fig. 3). In the case of the mixture Abs37+Pzr3, all modifications significantly positively influenced the results (Fig. 5). Differences were statistically significant (ANOVA/MANOVA test NIR $p<0.05$ ). In addition, between the bioreactors with modifications, differences in removal efficiency were observed and were statistically significant between the bioreactors "pH+sm" and "sm" $(p=0.047)$. 


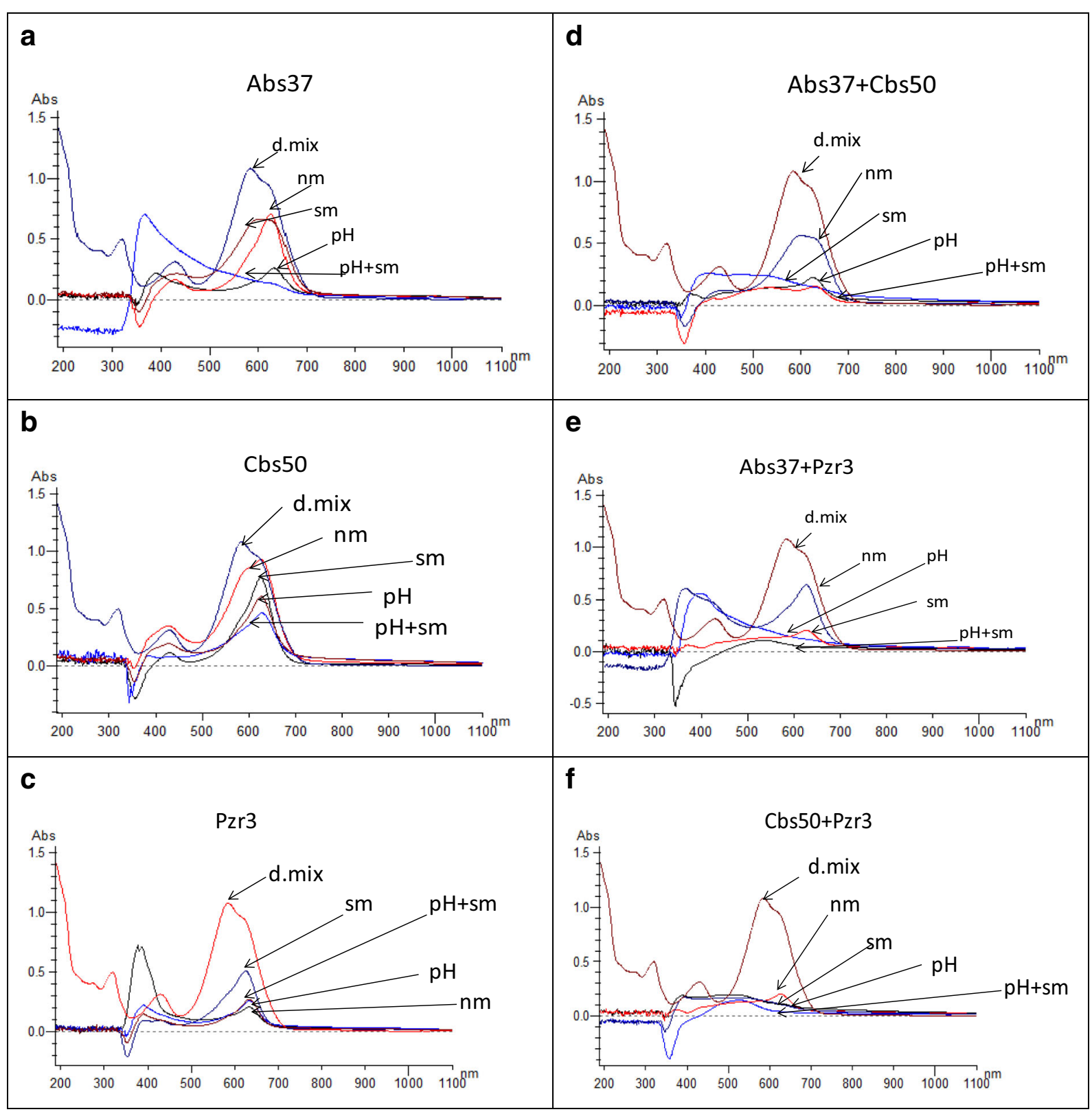

Fig. 9 The scans of UV-VIS of the samples from all reactors after finished decolourization processes (d.mix, dye mixture; nm, no modifications; $\mathrm{pH}, \mathrm{pH}$ correction; sm, supplementation with

nutrients; $\mathrm{pH}+\mathrm{sm}, \mathrm{pH}$ correction combined with the supplementation with nutrients)

It is worth emphasizing that Abs37+Pzr3 completely removed all doses of introduced dyes in shorter period of time, than the pure cultures or the mixture Abs37+ Cbs50.The mixture of obligatory aerobe Pzr3 and facultative anaerobe Abs 37 gave promising results. The sorption test results indicate that the physical sorption of dye may be playing a role in dye removal. The Abs37+Pzr3 had worse adsorption properties than

Abs37 used individually. It is probably the consequence of a lower density Abs37 biomass in mixture with Pzr3, which had no sorption abilities. The appearance of new peaks in the UV-VIS analyses (connected with the presence of new metabolites in wavelength range 365$400 \mathrm{~nm}$ ) and the retention of the natural colour of biomass of the bacterial mixture after the decolourization process, suggest that the dye mixture 
decolourization was mainly an enzymatic process (Fig. 9E). A smaller amount of peaks and the presence of differences in values of wavelengths with their maximum absorbance indicate a difference between the transformation processes and formed metabolites among the mixture and the pure cultures (Fig. 9A, C, E). In the case of the strain mixture Abs37+Pzr3, there was a positive impact of nutrient supplementation alone ("sm") and with the $\mathrm{pH}$ correction ("pH+sm"). In UVVIS scans of these samples, no metabolites were detected in contrast to sample "pH", where a high peak with maximal absorbance in wavelength $=400 \mathrm{~nm}$ was observed. This suggests that nutrient supplementation accelerated the decomposition of metabolites formed during the process. The UV-VIS scans also showed that in the bioreactor with no modifications ("nm"), the process leads to the accumulation of metabolites. Other results were shown on the UV-VIS scans for individual strains Abs37 and Pzr3 (Fig. 9A, C). The changes to growth conditions in the bioreactors positively influenced growth in bacteria number, especially in the reactor with $\mathrm{pH}$ correction combined with nutrient supplementation $(\mathrm{pH}+\mathrm{sm})$ and in the bioreactor supplemented by nutrients only (sm) (Fig. 5).

The third mixed bacterial culture was prepared from the facultative anaerobic strain Citrobacter sp. and obligate aerobic strain Pseudomonas putida (Cbs50+Pzr3) (Fig. 6). This culture was the most effective in dye mixture removal among all studied pure and mixed bacterial cultures. In the case of the Cbs50+Pzr3, all modifications had a significant positive influence (in contrast to strain Pzr3 when used as pure culture). However, the differences were visible only after the introduction of the fourth and fifth dose of dye mixture. The tested pure and mixed bacterial cultures (with exception of the mixture Cbs50+Pzr3) decolourized all four doses of dye mixture after 339 up to $507 \mathrm{~h}$. Whereas Cbs50+ Pzr3 removed all four doses of dyes after only $288 \mathrm{~h}$. The fifth portion of the dye mixture, introduced only to reactor with Cbs50+Pzr3, was completely removed, depending on modifications, after $409-458 \mathrm{~h}$. The differences between the efficiency of the decolourization processes in the bioreactors inoculated with Cbs50+ Pzr3 and the rest of the studied bioreactors were statistically significant (ANOVA/MANOVA test NIR $p<0.05$ ). Differences between removal results reached in the different bioreactors inoculated with Cbs50+Pzr3 were also observed. Statistically significant differences of dye decolourization efficiency were noted between the bioreactor "nm" and bioreactors "sm" and " $\mathrm{pH}+\mathrm{sm}$ " ( $p=0.031$ and $p=0.01$, respectively). The most effective modification was " $\mathrm{pH}+\mathrm{sm}$ ", while using only nutrient supplementation ("sm") or $\mathrm{pH}$ correction (" $\mathrm{pH}$ ") gave comparable results. In all bioreactors with growth condition modifications inoculated with Cbs50+Pzr3, the removal of dye mixture was complete and the results were the best of all mixed and pure cultures used in these studies. The sorption test results indicate that the physical sorption of dyes may be playing a role in their removal. The mixture Cbs50+Pzr3 showed worse adsorption properties than Cbs50 used individually. As Pzr3 lacks sorption ability, the lower results of dye sorption are likely the consequence of the lower density of biomass of Cbs50 in the mixtures compared to its monoculture (as was the case with Abs37+Pzr3). The appearance of new peaks in the UV-VIS analyses (connected with the presence of new metabolites in wavelength range 378-391 nm) was observed. These results and retention of the natural colour of the bacterial biomass after the decolourization process, confirm the enzymatic process (Fig. 9F). The smaller amount and height of peaks shown on the UV-VIS scans is observed (reactors with modifications as well as without modifications). Trace amount of metabolites confirms the positive influence of modifications on the activity of Cbs50+Pzr3 and the acceleration of their efficiency in the complete decomposition of the dye mixture. Changes to the growth conditions in the bioreactors positively influenced the growth of the total bacteria number (especially at bioreactors " $\mathrm{pH}+\mathrm{sm}$ " and "sm') which corresponded with the results of the decolourization (Fig. 6).

The scans of UV-VIS showed differences in the amount of peaks at different wavelengths with their maximum absorbance dependent on the modifications and cultures applied in a given bioreactor. This diversity of peaks points out the differences between transformation processes and formed metabolites in given bioreactors.

\subsection{Ecotoxicity Tests}

The results of the conducted zoo- and phytotoxicity test are presented in Table 5. A decrease of ecotoxicity was observed in all solutions after the decolourization process. The ecotoxicity of the initial solution of the dye mixture was estimated to be $\mathrm{V}$ class of toxicity (extremely toxic). The samples 
Table 5 The results of zootoxicity and phytotoxicity of solutions after decoluorization processes

\begin{tabular}{|c|c|c|c|c|}
\hline $\begin{array}{l}\text { Bacteria pure/mixed } \\
\text { culture }\end{array}$ & $\begin{array}{l}\text { Growth conditions } \\
\text { (modification) }\end{array}$ & $\begin{array}{l}\text { The residues of dye mixture } \\
\text { in solutions after } \\
\text { decolourization processes [mg/l] }\end{array}$ & $\begin{array}{l}\text { Toxicity class (TUa) } \\
\text { based on zootoxicity tests } \\
\text { (Daphnia magna) }\end{array}$ & $\begin{array}{l}\text { Toxicity class (TUa) } \\
\text { based on phytotoxicity } \\
\text { tests (Lemna minor) }\end{array}$ \\
\hline \multirow[t]{4}{*}{ Abs37 } & $\mathrm{bm}$ & $23.19 \pm 2.13$ & IV (12.20) & III (6.28) \\
\hline & $\mathrm{sm}$ & $12.13 \pm 0.79$ & IV (48.00) & IV (10.61) \\
\hline & $\mathrm{pH}$ & $5.91 \pm 0.54$ & III (8.64) & III (6.72) \\
\hline & $\mathrm{pH}+\mathrm{Sm}$ & $7.77 \pm 0.66$ & III (9.48) & III (8.60) \\
\hline \multirow[t]{4}{*}{ Cbs50 } & $\mathrm{bm}$ & $27.13 \pm 0.84$ & IV (69.14) & IV (17.40) \\
\hline & $\mathrm{sm}$ & $17.45 \pm 0.32$ & IV (68.25) & III (6.21) \\
\hline & $\mathrm{pH}$ & $12.12 \pm 0.9$ & IV (80.44) & III (4.48) \\
\hline & $\mathrm{pH}+\mathrm{Sm}$ & $3.44 \pm 0.12$ & III (5.88) & III (5.34) \\
\hline \multirow[t]{4}{*}{ Pzr3 } & $\mathrm{bm}$ & $3.12 \pm 0.3$ & IV (12.82) & III (5.65) \\
\hline & $\mathrm{sm}$ & $14.09 \pm 1.57$ & IV (58.82) & III (8.71) \\
\hline & $\mathrm{pH}$ & $4.55 \pm 0.86$ & III (8.71) & III (5.71) \\
\hline & $\mathrm{pH}+\mathrm{sm}$ & $7.55 \pm 0.54$ & III (9.75) & III (9.74) \\
\hline \multirow[t]{4}{*}{ Abs37+Cbs50 } & $\mathrm{bm}$ & $18.35 \pm 1.04$ & IV (65.67) & IV (55.47) \\
\hline & $\mathrm{sm}$ & $4.66 \pm 0.29$ & IV (74.34) & III $(8,66)$ \\
\hline & $\mathrm{pH}$ & $8.09 \pm 0.16$ & III (8.80) & III (4.64) \\
\hline & $\mathrm{pH}+\mathrm{sm}$ & $0.02 \pm 0.0$ & III (8.00) & III (4.55) \\
\hline \multirow[t]{4}{*}{ Abs37+Pzr3 } & $\mathrm{bm}$ & $20.60 \pm 0.79$ & IV (47.18) & IV (21.30) \\
\hline & $\mathrm{sm}$ & $1.32 \pm 0.2$ & III (9.55) & III (5.33) \\
\hline & $\mathrm{pH}$ & $0.59 \pm 0.01$ & IV (43.42) & III (3.33) \\
\hline & $\mathrm{pH}+\mathrm{sm}$ & $0.04 \pm 0.00$ & III (7.42) & II (0.92) \\
\hline \multirow[t]{4}{*}{ Cbs50+Pzr3 } & $\mathrm{bm}$ & $8.40 \pm 1.02$ & IV (21.30) & III (1.34) \\
\hline & $\mathrm{sm}$ & $1.71 \pm 0.00$ & IV (16.42) & II (0.88) \\
\hline & $\mathrm{pH}$ & $0.01 \pm 0.0$ & III (9.74) & II (0.78) \\
\hline & $\mathrm{pH}+\mathrm{sm}$ & $0.74 \pm 0.00$ & III (4.14) & II (0.62) \\
\hline Control & & $\begin{array}{l}80.00 \pm 0.00^{\mathrm{b}} \\
156.28 \pm 4.29^{\mathrm{c}}\end{array}$ & $\mathrm{V}(\text { n.e. })^{\mathrm{a}}$ & $\mathrm{V}(\text { n.e. })^{\mathrm{a}}$ \\
\hline
\end{tabular}

\footnotetext{
${ }^{\text {a }}$ Toxicity not estimated

${ }^{\mathrm{b}}$ Toxicity of initial $(80 \mathrm{mg} / \mathrm{l})$ dose of dye mixture

${ }^{\mathrm{c}}$ Toxicity of the total dose of dye mixture (sum of all doses $-170 \mathrm{mg} / \mathrm{l}$ ) introduced into bioreactors
}

after the decolourization process were more zootoxic than phytotoxic. The final ecotoxicity of the samples was different depending on the bacteria used and the modifications to the growth conditions. The zootoxicity was estimated as III or IV class of toxicity (toxic and high toxicity respectively) while the phytotoxicity was estimated between II-IV class of toxicity (II: low toxicity, III: toxic, IV: high toxicity). The higher zootoxicity of samples might be connected with the relative sensitivity of Daphnia magna to the presence of higher concentrations of different metabolites in the studied solutions, including different organic substances.
Many of the metabolites formed during the bacterial decolourization processes may be toxic when left untreated. This is especially true in the case of azo dyes due to the formation of aromatic amines and other benzene and naphthalene related compounds (Meerbergen et al. 2018; Saratale et al. 2011; Singh and Singh 2017).

The mixed cultures, which offered additional metabolic possibilities, increased the probability of complete removal of the dyes and their metabolites. This is very important for environmental safety (Elisangela et al. 2009; Meerbergen et al. 2018). Elisangela et al. (2009) described results of a Daphnia magna toxicity test. It was shown that decolourization of azo dyes under 
microaerophilic conditions caused a decrease in the toxicity of samples, but was not sufficient to lead to their detoxification.

In the case of the presented zootoxicity results, there were no significant differences between results from the reactors inoculated with pure or mixed cultures. The same is true in the case of phytotoxicity with the exception of the mixed culture Cbs50+Pzr3. For these samples, the results of the phytotoxicity were the lowest (mainly the II class of toxicity-low toxicity). This may be connected with the low amount of metabolites in this reactor in comparison with the rest (scan UV-Vis Fig. 9F). In general, for samples from the bioreactors with modification " $\mathrm{pH}$ " and " $\mathrm{pH}+\mathrm{sm}$ " the zootoxicity was lower (mainly III class of toxicity). In the case of phytotoxicity, the IV class of toxicity was estimated only in samples without modification. In the rest of the samples, the phytotoxicity was lower. A decrease of phytotoxicity was reported by Jadhav et al. (2010). Their results showed that the germination (\%) and length of pulmule and radicle of both T. aestivum and P. mugo seeds were reduced with untreated as compared with treated effluents. This shows that metabolites formed during the biodegradation of effluents are less toxic than compounds in the original effluents (Jadhav et al. 2010).

\section{Conclusions}

Growth conditions modifications had differing influences on the dye mixture decolourization efficiency by pure and mixed bacterial cultures. Generally, the most advantageous modification was the $\mathrm{pH}$ value correction combined with nutrient supplementation ("pH+sm"). The positive impact on decolourization efficiency was also observed in the case of $\mathrm{pH}$ correction alone, though the effect was increased when combined with nutrient supplementation across both pure and mixed cultures. Nutrient supplementation had a more positive impact on decolourization efficiency in the case of mixed bacterial cultures. The advantages of using a bacterial mixture are attributable to their ability to collectively carry out biodegradation tasks, which no individual pure strain can undertake successfully. In most cases, the mixtures of bacteria removed dyes with higher efficiency than the pure strains alone. In these bioreactors, dye removal was complete or almost complete and the lower concentrations of metabolites were noticed in solutions after decolourization as well as lower ecotoxicity. The significant differences were also noted between bacterial mixtures. Final dye removal by the two facultative anaerobes (Abs37+Cbs50) was not significantly worse than other mixed cultures, but did take longer. The most effective were the mixtures of a facultative anaerobe (either Abs37 or Cbs50) and an obligatory aerobe (Pzr3). Differences in strain metabolic properties complemented each other in the removal of the dye mixture and generated metabolites. The best solution was the mixture of Cbs50+Pzr3, which four portions of introduced dyes removed completely or almost completely already after $288 \mathrm{~h}$. Due to its high decolourization efficiency, Ps. putida may be considered a promising candidate to prepare the bio preparations (i.e. other mixed cultures).

Ecotoxicity tests showed the decrease of the zoo- and phytotoxicity of samples after the decolourization process. However, levels of ecotoxicity were still unsafe for the environment. The lowest zoo- and phytotoxicity was found in samples decolourized by the Cbs50+Pzr3 mixture. Despite the satisfying results of these decolourization processes, the high toxicity of postprocess solutions indicates the need for further research on high decolourization efficiency connected with the further or even complete detoxification of these solutions. The future purpose is also examination of possibilities of decolourization other also more complex dye mixture, with consideration of further improvement of process conditions.

Funding Information This research has been supported by the Faculty of Energy and Environmental Engineering Silesian University of Technology (project BK 08/080/BK-19/0067 (BK-258/ RIE-8/2019)).

Open Access This article is licensed under a Creative Commons Attribution 4.0 International License, which permits use, sharing, adaptation, distribution and reproduction in any medium or format, as long as you give appropriate credit to the original author(s) and the source, provide a link to the Creative Commons licence, and indicate if changes were made. The images or other third party material in this article are included in the article's Creative Commons licence, unless indicated otherwise in a credit line to the material. If material is not included in the article's Creative Commons licence and your intended use is not permitted by statutory regulation or exceeds the permitted use, you will need to obtain permission directly from the copyright holder. To view a copy of this licence, visit http://creativecommons.org/licenses/by/4.0/. 


\section{References}

Alexander, M. (2013). Advances in microbial ecology. New York: Springer-Verlag New York Inc.

Ali, H. (2010). Biodegradation of synthetic dyes - a review. Water, Air, and Soil Pollution, 213, 251-273.

An, S. Y., Min, S. K., Cha, I. H., Choi, Y. L., Cho, Y. S., Kim, C. H., \& Lee, Y. C. (2002). Decolorization of triphenylmethane and azo dyes by Citrobacter sp. Biotechnology Letters, 24, 1037-1040.

Balouiri, M., Sadiki, M., \& Ibnsouda, S. K. (2016). Methods for in vitro evaluating antimicrobial activity: a review. Journal of Pharmaceutical Analysis, 6, 71-79. https://doi.org/10.1016/j. jpha.2015.11.005.

Cao, J., Sanganyado, E., Liu, W., Zhang, W., \& Liu, Y. (2019). Decolorization and detoxification of direct blue $2 \mathrm{~B}$ by indigenous bacterial consortium. Journal of Environmental Management, 242, 229-237.

Chan, G. F., Rashid, N. A. A., Koay, L. L., Chang, S. Y., \& Tan, W. L. (2011). Identification and optimization of novel NAR-1 bacterial consortium for the biodegradation of Orange II. Insight Biotechnology, 1, 7-16.

Chang, J. S., Chou, C., Lin, Y., Ho, J., \& Hu, T. L. (2001). Kinetic characteristics of bacterial azo-dye decolorization by Pseudomonas luteola. Water Research, 35, 2841-2850.

Chang, J. S., Chen, B. Y., \& Lin, Y. S. (2004). Stimulation of bacterial decolorization of an Azo dye by extracellular metabolites from Escherichia coli strain $\mathrm{NO}_{3}$. Bioresource Technology, 91, 243-249.

Chen, K. C., Wu, J. Y., Liou, D. J., \& Huang, S. C. J. (2003). Decolorization of the textile dyes by newly isolated bacterial strains. Journal of Biotechnology, 101, 57-68.

Chen, C. H., Chang, C. F., \& Liu, S. M. (2010). Partial degradation mechanisms of malachite green and methyl violet B by Shewanella decolorationis NTOU1 under anaerobic conditions. Journal of Hazardous Materials, 177, 281-289.

Cui, D., Li, G., Zhao, D., Gu, X., Wang, C., \& Zhao, M. (2012). Microbial community structures in mixed bacterial consortia for azo dye treatment under aerobic and anaerobic conditions. Journal of Hazardous Materials, 221-222, 185-192.

Elisangela, F., Rea, Z., Fabio, D. G., Cristiano, R. M., Regina, D. L., \& Artur, C. P. (2009). Biodegradation of textile azo dyes by a facultative Staphylococcus arlettae strain VN-11 using a sequential microaerophilic/aerobic process. International Biodeterioration \& Biodegradation, 63, 280-288.

Eskandari, F., Shahnavaz, B., \& Mashreghi, M. (2019). Optimization of complete RB-5 azo dye decolorization using novel cold-adapted and mesophilic bacterial consortia. Journal of Environmental Management, 241, 91-98.

Ghaly, A. E., Ananthashankar, R., Alhattab, M., \& Ramakrishnan, V. V. (2014). Production, characterization and treatment of textile effluents: a critical review. Journal of Chemical Engineering \& Process Technology, 5(1), 1-19.

Hamid, M., \& Rehman, K. (2009). Potential applications of peroxidases. Review. Food Chemistry, 115, 1177-1186.

Hmer, P. W., McGeachie, J. M., Davies, M. J., \& Grounds, M. D. (2002). Evans blue dye as an in vivo marker of myofiber membrane permeability. Journal of Anatomy, 200, 69-79.

Ibrahim, H. M. M. (2018). Characterization of biosurfactants produced by novel strain of Ochrobactrum anthropic HM-1 and Citrobacter freundii HM-2 from used engine oil contaminated soil. Egyptian Journal of Petroleum, 27, 21-29. https://doi.org/10.1016/j.ejpe.2016.12.005.

Imam, A., Suman, S. K., Ghosh, D., \& Kanaujia, P. K. (2019). Analytical approaches used in monitoring the bioremediation of hydrocarbons in petroleum-contaminated soil and sludge. Trends in Analytical Chemistry, 118, 50-64. https://doi. org/10.1016/j.trac.2019.05.023.

Ito, T., Shimada, Y., \& Suto, T. (2018). Potential use of bacteria collected from human hands for textile dye decolorization. Water Resources and Industry, 20, 46-53.

Jadhav, S. U., Jadhav, M. U., Kagalkar, A. N., \& Govindwar, S. P. (2008). Decolorization of brilliant blue $\mathrm{G}$ dye mediated by degradation of the microbial consortium of Galactomyces geotrichum and Bacillus sp. Journal of the Chinese Institute of Chemical Engineers, 39, 563-570.

Jadhav, J. P., Kalyani, D. C., Telke, A. A., Phugare, S. S., \& Govindwar, S. P. (2010). Evaluation of the efficacy of a bacterial consortium for the removal of color, reduction of heavy metals and toxicity from textile dye effluent. Bioresource Technology, 101, 165-173.

Jagusiak, A., \& Pańczyk, T. (2019). Interaction of Congo Red, Evans Blue and Titan Yellow with doxorubicin ia aqueous solutions. A molecular dynamics study. Journal of Molecular Liquids, 279, 640-648.

Jang, M. S., Lee, Y. M., Kim, C. H., Lee, J. H., Kang, D. W., Kim, S. J., et al. (2005). Triphenylmethane reductase from Citrobacter sp. strain KCTC 18061P: purification, characterization, gene cloning, and overexpression of functional protein in Escherichia coli. Applied and Environmental Microbiology, 71(12), 7955-7960.

Joshi, T., Iyengar, L., Singh, K., \& Garg, S. (2008). Isolation, identification and application of novel bacterial consortium TJ-1 for the decolourization of structurally different azo dyes. Bioresource Technology, 99, 7115-7121.

Joshi, S. M., Inamdar, S. A., Telke, A. A., Tamboli, D. P., \& Govindwar, S. P. (2010). Exploring the potential of natural bacterial consortium to degrade mixture of dyes and textile effluent. International Biodeterioration \& Biodegradation, 64, 622-628.

Junnarkar, N., Murty, D. S., Bhatt, N. S., \& Madamwar, D. (2006). Decolorization of diazo dye direct red 81 by a novel bacterial consortium. World Journal of Microbiology \& Biotechnology, 22, 163-168.

Kalyani, D. C., Telke, A. A., Dhanve, R. S., \& Jadhav, J. P. (2009). Ecofriendly biodegradation and detoxification of reactive red 2 textile dye by newly isolated Pseudomonas sp. SUK1. Journal of Hazardous Materials, 163, 735-742.

Kaptanoglu, E., Okutan, O., Akbiyik, F., Solaroglu, I., Kilinc, A., \& Beskonakli, E. (2004). Corelation of injury severity and tissue Evans blue content, lipid peroxidation and clinical evaluation in acute spinal cord injury in rats. Journal of Clinical Neuroscience, 11(8), 879-885.

Karim, E., Dhar, K., \& Hossain, T. (2018). Decolorization of textile reactive dyes by bacterial monoculture and consortium screened from textile dyeing effluent. Journal of Genetic Engineering and Biotechnology, 16, 375-380.

Kodam, K. M., Soojhawon, I., Lokhande, P. D., \& Gawai, K. R. (2005). Microbial decolorization of reactive azo dyes under aerobic conditions. World Journal of Microbiology and Biotechnology, 21, 367-370. 
Koyani, R. D., Sanghvi, G. V., Sharma, R. K., \& Rajput, K. S. (2013). Contribution of lignin degrading enzymes in decolourisation and degradation of reactive textile dyes. International Biodeterioration and Biodegradation, 77, 1-9.

Kuhad, R. C., Gupta, R., \& Khasa, Y. P. (2012). Microbial decolourization of colored industrial effluents. In $\mathrm{T}$. Satyanarayana, B. N. Johri, \& A. Prakash (Eds.), Micoroorganisms in environmental management - microbes and environment (pp. 787-815). Berlin, ch.35: Springer Netherlands.

Liao, H. Y., Chien, C. C., Tang, P., Chen, C. C., Chen, C. Y., \& Chen, S. C. (2018). The integrated analysis of transcriptome and proteome for exploring the biodegradation mechanism of 2,4,6-trinitrotoluene by Citrobacter sp. Journal of Hazardous Materials, 349, 79-90. https://doi.org/10.1016/j. hazmat.2018.01.039.

Meerbergen, K., Willems, K. A., Dewil, R., Impe, J. V., Appels, L., \& Lievens, B. (2018). Isolation and screening of bacterial isolates from wastewater treatment plants to decolorize azo dyes. Journal of Biosence and Bioengineering, 125(4), 448-456.

Modi, H. A., Rajput, G., \& Ambasana, C. (2010). Decolorization of water soluble azo dyes by bacterial cultures, isolated from dye house effluent. Bioresource Technology, 101, 6580-6583.

Mohana, S. V., Shrivastav, S., Divecha, J., \& Madamwar, D. (2008). Response surface methodology for optimization of medium for decolorization of textile dye direct black 22 by a novel bacterial consortium. Bioresource Technology, 99, 562-569.

Moosvi, S., Keharia, H., \& Madamwar, D. (2005). Decolourization of textile dye reactive Violet 5 by a newly isolated bacterial consortium RVM 11.1. World Journal of Microbiology and Biotechnology, 21, 667-672.

Oliveira, D. P., Carneiro, P. A., Sakagami, M. K., Zanoni, M. V., \& Umbuzeiro, G. A. (2007). Chemical characterization of a dye processing plant effluent-identification of the mutagenic components. Mutation Research, 626(1-2), 135-142.

Oranusi, N. A., \& Ogugbue, C. J. (2005). Effect of cosubstrates on primary biodegradation of triphenymethane dyes by Pseudomonas. Affrican Journal of Applied Zoology and Environmental Biotechnology, 7, 38-44.

Pandey, A., Singh, P., \& Iyengar, L. (2007). Bacterial decolourization and degradation of azo dyes. International Biodeterioration and Biodegradation, 59, 73-84.

Pearce, C. I., Lloyd, J. R., \& Guthrie, J. T. (2003). The removal of colour from textile wastewater using whole bacterial cells: a review. Dyes and Pigments, 58, 179-196.

Phugare, S. S., Kalyani, D. C., Patil, A. V., \& Jadhav, J. P. (2011). Textile dye degradation by bacterial consortium and subsequent toxicological analysis of dye and dye metabolites using cytotoxicity, genotoxicity and oxidative stress studies. Journal of Hazardous Materials, 186, 713-723.

Przystaś, W., Zabłocka-Godlewska, E., \& Grabińska-Sota, E. (2012). Biological removal of Azo and triphenylmethane dyes and toxicity of process by-products. Water, Air, and Soil Pollution, 223, 1581-1592.

Przystaś, W., Zabłocka-Godlewska, E., \& Grabińska-Sota, E. (2013). Effectiveness of dyes removal by mixed fungal cultures and toxicity of their metabolites. Water, Air, and Soil Pollution, 224(5), 1534-1543.
Przystaś, W., Zabłocka-Godlewska, E., \& Grabińska-Sota, E. (2015). Efficacy of fungal decolorization of a mixture of dyes belonging to different classes. Brazilian Journal of Microbiology, 46(2), 415-424.

Rajee, O., \& Patterson, J. (2011). Decolorization of azo dye (Orange MR) by an autochthonous bacterium Micrococcus sp. DBS2. Indian Journal of Microbiology, 51(2), 159-163.

Ramadass, K., Megharaj, M., Venkateswarlu, K., \& Naidu, R. (2018). Bioavailability of weathered hydrocarbons in engine oil-contaminated soil: impact of bioaugmentation mediated by Pseudomonas spp. on bioremediation. Science of The Total Environment, 636, 968-974. https://doi.org/10.1016/j. scitotenv.2018.04.379.

Rehman, R., Mahmud, T., \& Irum, M. (2015, Article ID 126036). Brilliant green dye elimination from water using Psidium guajava leaves and Solanum tuberosum peels as sorbent in environmentally benign way. Journal of Chemistry, 2015, 18. https://doi.org/10.1155/2015/126036.

Ren, S., Guo, J., Zeng, G., \& Sun, G. (2006). Decolorization of triphenylmethane, azo and antraquinone dyes by a newly isolated Aeromonas hydrophila strain. Applied Microbiology and Biotechnology, 72, 1316-1321.

Salimizadeh, M., Shirvani, M., Shariatmadari, H., Niaeen, M., \& Leili Mohebi Nozar, S. (2018). Coupling of bioaugmentation and phytoremediation to improve PCBs removal from a transformer oil-contaminated soil. International Journal of Phytoremediation, 20(7), 658-665. https://doi.org/10.1080 /15226514.2017.1393388.

Sanders, E. R. (2012). Aseptic laboratory techniques: plating methods. Journal of Visualized Experiments, 63, 1-18. https://doi.org/10.3791/3064.

Saratale, R. G., Saratale, G. D., Chang, J. S., \& Govindwar, S. P. (2009). Ecofriendly decolorization and degradation of reactive green 19A using Micrococcus glutamicus NCIM-2168. Bioresource Technology, 110, 3897-3905.

Saratale, R. G., Saratale, G. D., Chang, J. S., \& Govindwar, S. P. (2011). Bacterial decolourization and degradation of azo dyes: a review. Journal of the Taiwan Institute of Chemical Engineers, 42, 138-157.

Sawhney, R., \& Kumar, A. (2011). Congo red (azo dye) decolorization by local isolate VTII inhabiting dye effluent exposed soil. International Journal of Environmental Sciences, 1, 1261-1267.

Sharma, D. K., Saini, H. S., Singh, M., Chimni, S. S., \& Chandha, B. S. (2004). Isolation and characterization of microorganisms capable of decolorizing various triphenylmethane dyes. Journal of Basic Microbiology, 44(1), 59-65.

Silveira, E., Marques, P. P., Silva, S. S., Lima-Filho, J. L., Porto, A. L. F., \& Tambourgi, E. B. (2009). Selection of Pseudomonas for industrial textile dyes decolourization. International Biodeterioration and Biodegradation, 63, 230-235. https://doi.org/10.1016/j.ibiod.2008.09.007.

Singh, P. K., \& Singh, R. L. (2017). Bio-removal of Azo dyes: a review. International Journal of Applied Science Biotechnology, 5(2), 108-126. https://doi.org/10.3126 /ijasbt.v5i2.16881.

Singh, S., Pakshirajan, K., \& Daverey, A. (2010). Enhanced decolourization of direct red-80 dye by the white rot fungus Phanerochaete chrysosporium employing sequential design of experiments. Biodegradation, 21, 501-511. 
Sneha, U., Poornima, R., \& Sridhar, S. (2013). Decolorization of synthetic textile dyes using Pseudomonas putida. Journal of Chemical and Pharmaceutical Research, 5(5), 219-225.

Solis, M., Solis, A., Perez, H. I., Manjarrez, N., \& Flores, M. (2012). Microbial decolouration of azo dyes: a review. Process Biochemistry, 47, 1723-1748.

Somasiri, W., Ruan, W., Xiufen, L., \& Jian, C. (2006). Decolourization of textile wastewater containing acid dyes in UASB reactor system under mixed anaerobic granular sludge. Electronic Journal of Environmenatl, Agricultural and Food Chemistry, 5(1), 1224-1234.

Srinivasan, A., \& Viraraghavan, T. (2010). Decolorization of dye wastewater by biosorbents: a review. Journal of Environmental Management, 91, 1915-1929.

Tandlich, R., Brezna, B., \& Dercova, K. (2001). The effect of terpenes on the biodegradation of PCBs by Pseudomonas stutzeri. Chemosphere, 44(7), 15-47-55. https://doi. org/10.1016/S0045-6535(00)00523-3.

Tony, B. D., Goyal, D., \& Khanna, S. (2009). Decolorization of textile azo dyes by aerobic bacterial consortium. International Biodeterioration and Biodegradation, 63, 62469. https://doi.org/10.1016/j.ibiod.2009.01.003.

Vijayaraghavan, K., \& Yun, Y. S. (2008). Bacterial biosorbents and biosorption. Research review paper. Biotechnology Advances, 26, 266-291.

Vijaykumar, M. H., Vaishampayan, P. A., Shouche, Y. S., \& Karegoudar, T. B. (2007). Decolourization of naphtalenecontaining sulfonated azo dyes by Kerstersia sp. strain VKY1. Enzyme and Microbial Technology, 40, 204-211.

Waghmode, T. R., Kurade, M. B., Khandare, R. V., \& Govindwar, S. P. (2011). A sequential aerobic/microaerophilic decolorization of sulfonated mono azo dye golden yellow HER by microbial consortium $\mathrm{GG}-\mathrm{BL}$. International Biodeterioration \& Biodegradation, 65, 1024-1034.

Wang, H. J., Su, Q., Zheng, X. W., Tian, Y., Xiong, X. J., \& Zheng, T. L. (2009). Bacterial decolorization and degradation of the reactive dye reactive red 180 by Citrobacter sp. CK3. International Biodeterioration and Biodegradation, 63, 395-399.

Wang, J., Gao, F., Liu, Z., Qiao, M., Niu, X., Zhang, K. Q., \& Huang, X. (2012). Pathway and molecular mechanisms for malachite green biodegradation in Exiguobacterium sp.
MG2. PLoS ONE, 7(12). https://doi.org/10.1371/journal. pone. 0051808 .

Wu, J., Jung, B.-G., Kim, K.-S., Lee, Y.-C., \& Sung, N.-C. (2009a). Isolation and characterization of Pseudomonas otitidis WL-13 and its capacity to decolorize triphenylmethane dyes. Journal of Environmental Sciences, 21, 960-964.

Wu, Y., Xiao, X., Xu, C., Cao, D., \& Du, D. (2012). Decolorization and detoxification of sulfonated triphenylmethane dye aniline blue by Shewanella oneidensis MR-1 under anaerobic conditions. Applied Microbiology and Biotechnology. https://doi.org/10.1007/s00253-012-4476-3.

Younes, S., Bouallagui, Z., \& Sayadi, S. (2012). Catalytic behavior and detoxifying ability of an atypical homotrimeric laccase from the thermophilic strain Scytalidium thermophilumon selected azo and triarylmethane dyes. Journal of Molecular Catalysis B: Enzymatic, 79, 41-48.

Zabłocka-Godlewska, E., Przystaś, W., \& Grabińska-Sota, E. (2009). Decolourization of triphenylmethane dyes and ecotoxicity of their end products. Environment Protection Engineering, 35(1), 161-169.

Zabłocka-Godlewska, E., Przystaś, W., \& Grabińska-Sota, E. (2012). Decolourization of diazo Evans blue by two strains of Pseudomonas fluorescens isolated from different wastewater treatment plants. Water, Air, and Soil Pollution, 223(8), 5259-5266.

Zabłocka-Godlewska, E., Przystaś, W., \& Grabińska-Sota, E. (2014). Decolourisation of different dyes by two Pseudomonas strains under various growth conditions. Water, Air, and Soil Pollution, 225, 1846-1859.

Zabłocka-Godlewska, E., Przystaś, W., \& Grabińska-Sota, E. (2015). Dye decolourization using two Klesiella strains. Water Air and Soil Pollution, 226, 2249-2263.

Zheng, M., Wang, W., Hayes, M., Nydell, A., Tarr, M. A., Van Bael, S., \& Papadopoulos, K. (2018). Degradation of Macondo 252 oil by endophytic Pseudomonas putida. Journal of Environmental Chemical Engineering, 6, 643648. https://doi.org/10.1016/j.jece.2017.12.071.

Publisher's Note Springer Nature remains neutral with regard to jurisdictional claims in published maps and institutional affiliations. 